OLGA REGIANE PILEGIS

SAÚDE MENTAL E TRABALHO: REDUÇÃO PROGRESSIVA DOS RISCOS PSICOSSOCIAIS LABOR-AMBIENTAIS

Dissertação de Mestrado

Orientador: Professor Associado Dr. Guilherme Guimarães Feliciano

UNIVERSIDADE DE SÃO PAULO

FACULDADE DE DIREITO

São Paulo-SP

2018 
OLGA REGIANE PILEGIS

\section{SAÚDE MENTAL E TRABALHO: REDUÇÃO PROGRESSIVA DOS RISCOS PSICOSSOCIAIS LABOR-AMBIENTAIS}

Dissertação apresentada à Banca Examinadora do Programa de Pós-Graduação em Direito, da Faculdade de Direito da Universidade de São Paulo, como exigência parcial para obtenção do título de Mestre em Direito, na área de concentração Direito do Trabalho e da Seguridade Social, sob a orientação do Professor Associado Dr. Guilherme Guimarães Feliciano.

UNIVERSIDADE DE SÃO PAULO

FACULDADE DE DIREITO

São Paulo-SP

2018 
Autorizo a reprodução e divulgação total ou parcial deste trabalho, por qualquer meio convencional ou eletrônico, para fins de estudo e pesquisa, desde que citada a fonte.

Ficha Catalográfica

Faculdade de Direito da Universidade de São Paulo

Pilegis, Olga Regiane

Saúde mental e trabalho: redução progressiva dos riscos psicossociais labor-ambientais / Olga Regiane Pilegis - São Paulo: USP / Faculdade de Direito, 2018.

$254 f$.

Orientador: Professor Associado Dr. Guilherme Guimarães Feliciano.

Dissertação (Mestrado), Universidade de São Paulo, USP, Programa de Pós-Graduação em Direito, Direito do Trabalho e da Seguridade Social, 2018.

1. Saúde mental do trabalhador. 2. Meio ambiente do trabalho. 3. Prevenção dos riscos psicossociais labor-ambientais 4. Princípio da melhoria contínua. I. Feliciano, Guilherme Guimarães. II. Título. 
Nome: PILEGIS, Olga Regiane

Título: Saúde mental e trabalho: redução progressiva dos riscos psicossociais laborambientais

Dissertação apresentada à Banca Examinadora do Programa de Pós-Graduação em Direito, da Faculdade de Direito da Universidade de São Paulo, como exigência parcial para obtenção do título de Mestre em Direito, na área de concentração Direito do Trabalho e da Seguridade Social, sob a orientação do Professor Associado Dr. Guilherme Guimarães Feliciano.

Aprovado em:

Banca Examinadora

Prof.Dr. Instituição:

Julgamento: Assinatura:

Prof.Dr. Instituição:

Julgamento: Assinatura:

Prof.Dr. Instituição:

Julgamento: Assinatura: 
Para Isabella e Gabriel, amados filhos. Pelo apoio e compreensão durante os inúmeros momentos de ausência dedicados à conclusão desta pesquisa. 


\section{AGRADECIMENTOS}

A realização desta pesquisa não teria se concretizado sem o apoio incondicional recebido do Tribunal Regional do Trabalho da 15 Região - TRT15 e da Escola Judicial EJUD do mesmo Regional, especialmente em razão da licença-estudo autorizada com fundamento na regra do artigo 73, inciso I da LC n.35/1979, após aprovação em sessão plenária.

Impossível também seria a conclusão sem o rumo preciso sempre brilhantemente indicado pelo mestre e orientador, Dr. Guilherme Guimarães Feliciano, profissional da mais alta competência e notabilíssimo saber jurídico, qualidades sempre ressaltadas por todos os que gozam do privilégio de receber seus valiosos ensinamentos. Nas muitas vezes em que o desânimo bateu à porta e o cansaço esteve prestes a vencer, seu incentivo amigo e acolhedor permitiu que esta caminhada chegasse - finalmente - a bom termo.

A tarefa de enfrentar e dissecar o verdadeiro cipoal em que se emaranham nossas Normas Regulamentadoras (normas técnico-jurídicas em matéria de proteção à saúde e segurança dos trabalhadores) jamais teria sido enfrentada, não fosse o incentivo do Prof. Dr. Homero Batista Mateus da Silva, que com simpatia e leveza conseguiu tornar simples o desafio.

Entender as agruras do homem-que-vive-do-trabalho para além dos textos legais, foi tarefa prazerosa e enriquecedora, alcançada por mérito exclusivo do estimado e competentíssimo Prof. Dr. Ricardo Luiz Coltro Antunes, da Faculdade de Sociologia do IFCH - UNICAMP/SP.

Compreender o meio ambiente de trabalho como algo mais do que o simples local de execução das atividades laborativas é mérito que devo aos ensinamentos do Professor Dr. Ney Stany Morais Maranhão, da Universidade Federal do Pará, que mesmo a milhares de quilômetros de distância conseguiu dissipar nuvens de dúvidas com sua palavra virtual paciente e amiga.

Os estudos e debates hauridos nos acolhedores encontros quinzenais do NTADT Núcleo de Pesquisa e Extensão "O Trabalho Além do Trabalho" foram primordiais para a compreensão das dinâmicas que alimentam o ciclo de marginalização social dos trabalhadores. Muito mais do que isso, permitiram a formação de amizades que agora 
seguem absolutamente imprescindíveis no restante da minha jornada. Sem o carinho de vocês, tudo teria sido bem menos divertido e estimulante.

Colegas de classe e estimados Professores do Instituto de Psiquiatria do Hospital das Clínicas da Faculdade de Medicina da Universidade de São Paulo - Ipq HCFMUSP também foram parceiros insuperáveis na elucidação dos conceitos médico-periciais essenciais à compreensão do tema central deste estudo.

A todos, o meu mais profundo e sincero agradecimento. 
A liberdade não se dá - dizem - ela se conquista. O mesmo acontece com relação à organização do trabalho. É provável que não exista solução ideal e que, aqui, como em tudo mais, seja sobretudo a evolução a portadora de esperança. Considerando o lugar dedicado ao trabalho na existência, a questão é saber que tipo de homens a sociedade fabrica através da organização do trabalho. Entretanto, o problema não é, absolutamente, criar novos homens, mas encontrar soluções que permitam pôr fim à desestruturação de um certo número deles pelo trabalho. (DEJOURS, 1992, p. 139) 
PILEGIS, Olga Regiane. Saúde mental e trabalho: redução progressiva dos riscos psicossociais labor-ambientais. 2018. 254f. Dissertação (Mestrado) - Faculdade de Direito, Universidade de São Paulo, São Paulo, 2018.

\section{RESUMO}

Esta pesquisa tem como objetivo analisar o direito fundamental à saúde mental do trabalhador, sob a perspectiva de sua promoção mediante a redução progressiva dos riscos psicossociais presentes nos ambientes de trabalho. Argumenta-se que as metamorfoses produtivas ocorridas no modo de produção capitalista no cenário pós-fordista alteraram a organização do trabalho de um modo precarizante, objetiva e subjetivamente, trazendo alta nocividade para a saúde mental dos trabalhadores. Os estudos da PDT - Psicodinâmica do Trabalho (escola dejouriana) são tomados como referencial para a explicação de como essa conjunção de precarizações pode provocar um desequilíbrio sistêmico labor-ambiental apto a produzir sofrimento, psicopatologias e até mesmo o suicídio de trabalhadores. Considera-se que a aplicação de estratégias prevencionistas em múltiplos níveis de ação, guiada pelos postulados clássicos do Direito Ambiental, pode colaborar para preservar a higidez psicossocial labor-ambiental. Necessário antes superar alguns problemas nacionais considerados entraves para a mais adequada tutela desse direito, como a obsolescência e insuficiência do arcabouço normativo a ele relacionado, a alta estigmatização dos portadores de transtornos mentais, a escassez e inefetividade das políticas públicas em saúde mental relacionada ao trabalho e as soluções apresentadas a posteriori, centradas no paradigma da culpabilização da vítima e na monetização dos riscos e agravos. Propõe-se uma atuação preventiva e transdisciplinar, pautada pelo princípio da melhoria contínua ou do risco mínimo regressivo (artigo $4^{\circ}$ da Convenção $n^{\circ} 155$ da OIT e artigo $7^{\circ}$, XXII da CRFB), sugerindo-se também a necessidade de modificações legislativas, administrativas e organizacionais, assim como a adoção de um novo olhar do Poder Judiciário para as questões envolvendo o tema da saúde mental relacionada ao trabalho, tudo a constituir um grande desafio interinstitucional para as próximas décadas.

Palavras-chave: Saúde mental do trabalhador. Meio ambiente do trabalho. Prevenção dos riscos psicossociais labor-ambientais. Princípio da melhoria contínua. 
PILEGIS, Olga Regiane. Mental health and work: progressive reduction of laborenvironmental psychosocial risks. 2018. 254f. Dissertation (Master's degree) - Law School, University of São Paulo, São Paulo, 2018.

\begin{abstract}
This study aims to analyze the fundamental right to worker's mental health from the perspective of its promotion through the progressive reduction of the psychosocial risks present in working environments. It is argued that the production metamorphoses occurring in the capitalist mode of production in the post-Ford era scenario have changed the organization of labor in a precarious manner, both objectively and subjectively, bringing great harm to workers' mental health. PDTs - Labor Psychodynamic (dejouriana School) studies are references to explain how such instabilities can cause systemic laborenvironmental imbalance capable of producing suffering, psychopathologies and even worker suicides. It is considered that the application of preventive strategies in multiple levels of action, guided by the classic postulates of Environmental Law, can collaborate to preserve labor-environmental psychosocial health. But first, it is necessary to overcome certain national problems that are considered obstacles to the proper protection of such rights, such as the obsolescence and insufficiency of the normative framework related to it, the high stigmatization of people with mental disorders, the scarcity and ineffectiveness of public mental health policies related to work and the solutions presented afterwards centered in the paradigm of blaming the victim and in the monetization of risks and hazards. A preventive and transdisciplinary approach is proposed, guided by the principle of continuous improvement or regressive minimal risk (article 4th of Convention No. 155 of the ILO and article 7th, XXII of the Constitution), also suggesting the need for legislative, administrative and organizational changes, as well as the adoption of a new perspective from the Judiciary to issues involving mental health related to work, all of which constitute a major interinstitutional challenge for the next decades.
\end{abstract}

Keywords: Worker's mental health; Working environment; Prevention of laborenvironmental psychosocial risks; Principle of continuous improvement. 


\section{LISTA DE ILUSTRAÇÕES}

FIGURA 1: Distribuição dos acidentes de trabalho registrados no INSS conforme diagnósticos de TMCRT mais frequentes e quantitativo absoluto/relativo de notificações sem emissão de Comunicação de Acidente de Trabalho, 20112013.

FIGURA 2: Distribuição das concessões anuais de benefícios previdenciários relacionados à saúde mental do trabalhador, no período 2008-2011

FIGURA 3: Doenças mentais como principal causa de aposentadoria precoce na Alemanha, no período 1995-2003

FIGURA 4: Relação dinâmica saúde mental x doença mental .51

FIGURA 5: Relação simplificada de causalidades dos fatores psicossociais na empresa .91

FIGURA 6: Gráfico de Karasek - Modelo Demanda-Controle (Job Strain Model). 173

FIGURA 7: Modelo da Organização Mundial da Saúde - OMS para preservação de ambientes de trabalho saudáveis 


\section{LISTA DE TABELAS}

TABELA 1: Taxonomia dos riscos psicossociais relacionados ao trabalho .97

TABELA 2: Situações de fato usualmente presentes nos ambientes deteriorados pela SLN - Síndrome Loco-Neurótica.

TABELA 3: Alterações ocorridas na organização do trabalho de juízes brasileiros a partir da implantação do Processo Judicial Eletrônico - PJE e impactos produzidos na saúde desses profissionais

TABELA 4: Lista oficial dos transtornos mentais e comportamentais relacionados ao Trabalho (TMCRT) e seus agentes patogênicos.

TABELA 5: Fatores de risco potencialmente presentes nos ambientes de trabalho 169

TABELA 6: Estratégias de manejo dos fatores de risco psicossocial presentes nos ambientes de trabalho, em níveis progressivos de intervenção 


\section{LISTA DE ABREVIATURAS E SIGLAS}

ACGIH - American Conference of Governmental Industrial Hygienists

AMA - American Medical Association

APA - American Psychiatric Association

CAT - Comunicação de Acidente de Trabalho

CBO - Classificação Brasileira de Ocupações

CFRB - Constituição da República Federativa do Brasil, de 05.10.1988

CID-10 - Classificação Estatística Internacional de Doenças e Problemas Relacionados à

Saúde $-10^{\mathrm{a}}$ revisão

CIF - Classificação Internacional de Funcionalidade, Incapacidade e Saúde

CIPA - Comissão Interna de Prevenção de Acidentes

CLT - Consolidação das Leis do Trabalho

CNAE - Classificação Nacional de Atividades Econômicas

CPC - Código de Processo Civil (Brasil, Lei n.13.015, de 16-3-2015)

DORT - Distúrbios Osteomusculares Relacionados ao Trabalho

EC - emenda constitucional

EPI - Equipamentos de Proteção Individual

FUNDACENTRO - Fundação Jorge Duprat Figueiredo de Segurança e Medicina do Trabalho

g.n. - grifos (negritos) nossos

ILO - International Labour Organization

MTE - Ministério do trabalho e Emprego (Brasil)

NIOSH - National Institute for Occupational Safety and Health

NR - Norma Regulamentadora

OIT - Organização Internacional do Trabalho

OIT - Organização Internacional do Trabalho

OMS - Organização Mundial da Saúde

ONU - Organização das Nações Unidas

OSHA - Occupational Safety and Health Administration

p.ex. - por exemplo

PCMSO - Programa de Controle Médico de Saúde Ocupacional

PIDESC - Pacto Internacional sobre Direitos Econômicos, Sociais e Culturais 
PL - Projeto de Lei

PLS - Projeto de Lei (origem no Senado Federal)

PPRA - Programa de Prevenção de Riscos Ambientais

RENAST - Rede Estadual de Atenção à Saúde do Trabalhador

RPSLA - Riscos Psicossociais Labor-Ambientais

SAT - Seguro Acidente de Trabalho

SESMT - Serviços Especializados em Engenharia de Segurança e em Medicina do Trabalho

SIPAT - Semana Interna de Prevenção de Acidentes

SMRT - Saúde Mental Relacionada ao Trabalho

SST - Saúde e Segurança no Trabalho

SUS - Sistema Único de Saúde

TMCRT - Transtornos Mentais e Comportamentais Relacionados ao Trabalho

TST - Tribunal Superior do Trabalho (Brasil)

v.g. - verbi gratia

WHO - World Health Organization 


\section{SUMÁRIO}

\section{METAMORFOSES NA ORGANIZAÇÃO DO TRABALHO CONTEMPORÂNEO}

E A PRECARIZAÇÃO DA SAÚDE MENTAL DO TRABALHADOR .............................. 21

1.1. Dialética do trabalho, entre o sofrimento e a autorrealização de si .....................................................22

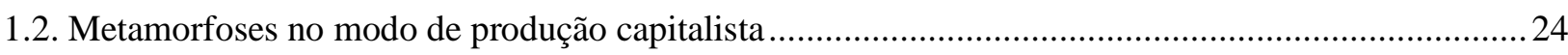

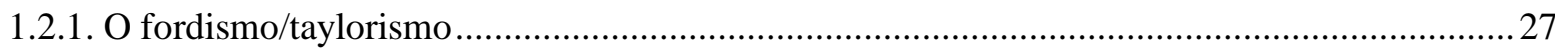

1.2.2. O toyotismo e a manipulação da subjetividade do trabalhador .................................................29

1.2.3. Gerencialismo, qualidade total e ideologia da excelência......................................................... 32

1.3. Superexploração do trabalho e precarização da saúde mental dos trabalhadores ................................. 35

1.4. A escalada global do adoecimento mental relacionado ao trabalho e suas consequências,

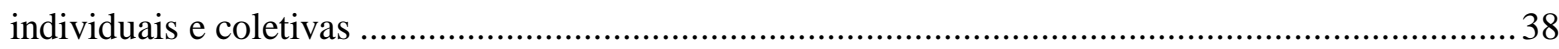

2. PROTEÇÃo AO DiReito FUNDAMENTAL À SAÚde MENTAL DO TRABALHADOR PELA APLICAÇÃo dOS POSTUladOS CLÁSSICOS DE

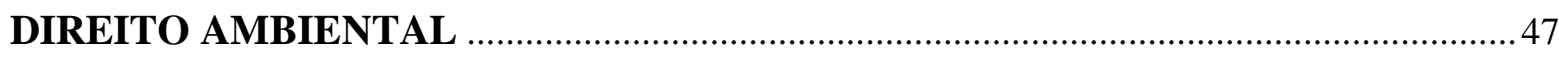

2.1. Evolução dos conceitos de saúde mental e saúde mental do trabalhador .............................................47

2.2. Estudos interdisciplinares. Saúde Mental Relacionada ao Trabalho - SMRT e Psicologia da

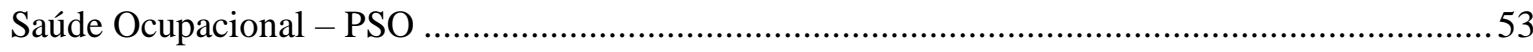

2.3. Arcabouço normativo de proteção à saúde mental no trabalho.........................................................55

2.3.1. Normas de direito internacional em matéria de saúde mental do trabalhador ..........................57

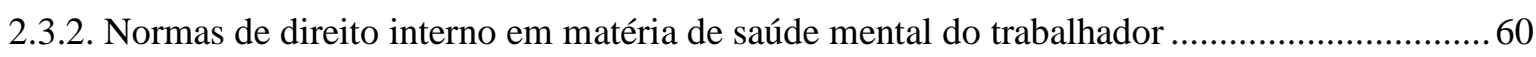

2.4. O direito fundamental à saúde mental do trabalhador em suas diversas dimensões..........................67

2.5. Aplicação dos postulados clássicos de direito ambiental para preservação da higidez

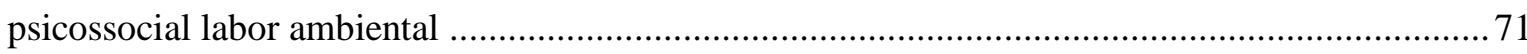

\section{A PRESENÇA DOS RISCOS PSICOSSOCIAIS E O DESEQUILÍBRIO} SISTÊMICO DA DIMENSÃO IMATERIAL LABOR-AMBIENTAL ………………........ 85

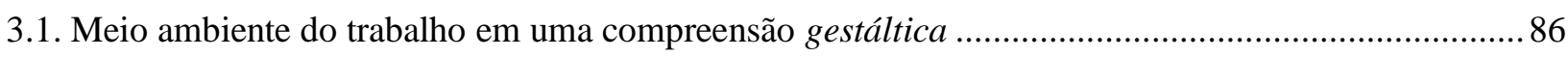

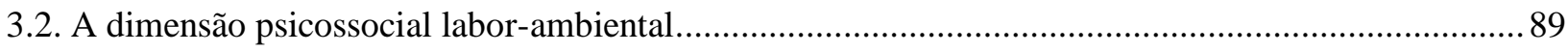

3.3. Os emergentes riscos psicossociais labor-ambientais RPSLA ......................................................... 92

3.4. O desequilíbrio sistêmico na dimensão psicossocial labor-ambiental.............................................99

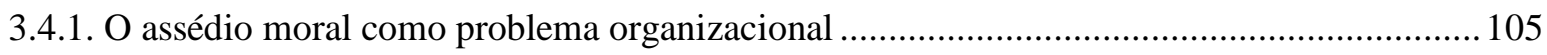

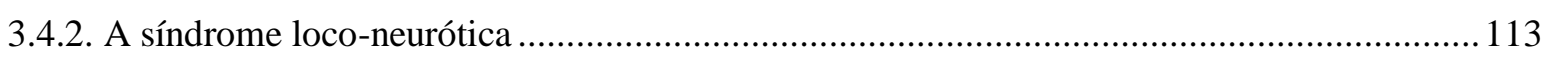

\section{DO SOFRIMENTO NO TRABALHO AO ADOECIMENTO MENTAL DOS}

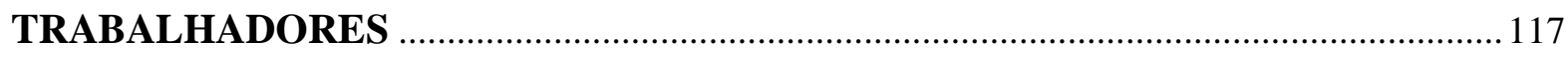

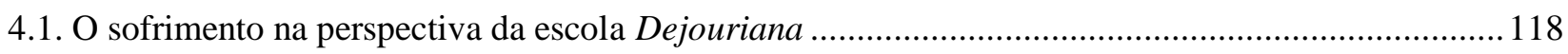

4.1.1. O apagamento da ética e a banalização do mal.................................................................... 120

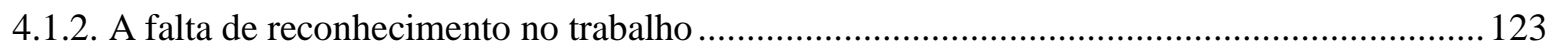


4.1.3. A percepção de injustiças nos ambientes de trabalho

4.1.4. A distorção comunicacional nos ambientes de trabalho 129

4.2. O sofrimento coletivo no trabalho exemplificado em três casos reais ...............................................132

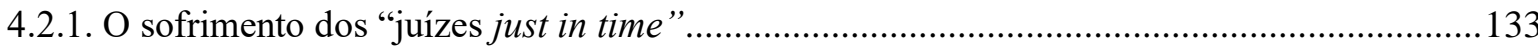

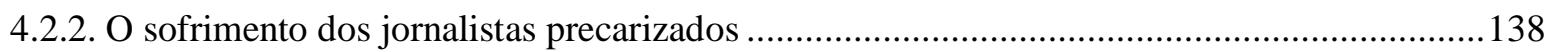

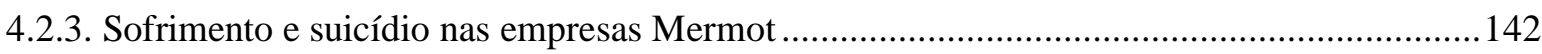

4.3. Descompensações fisiopsíquicas decorrentes do sofrimento no trabalho ……..................................148

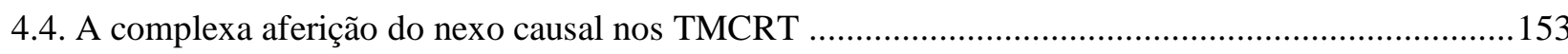

5. PREVENÇÃO E PROMOÇÃO DA SAÚdE MENTAL DO TRABALHADOR PELA REDUÇÃO PROGRESSIVA DOS RISCOS PSICOSSOCIAIS LABOR-

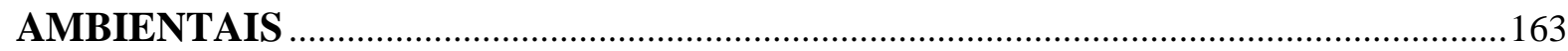

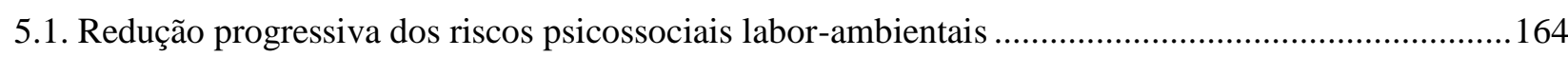

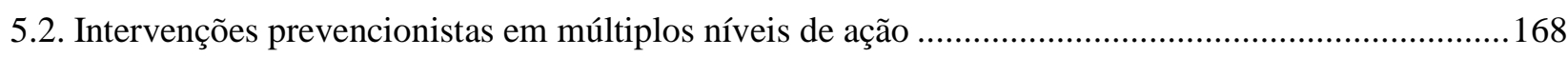

5.3. Problemas nacionais contemporâneos em saúde mental relacionada ao trabalho ............................... 180

5.3.1. Obsolescência e insuficiência do arcabouço normativo protecionista ...................................180

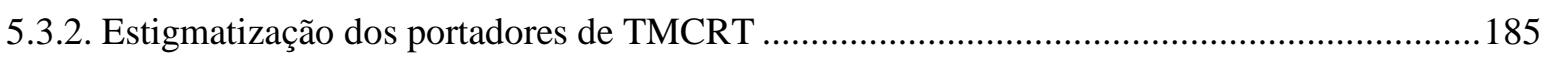

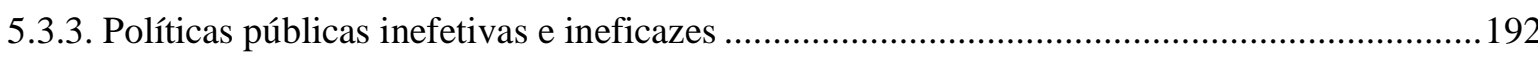

5.4. O papel do Judiciário em matéria de saúde mental relacionada ao trabalho ......................................199

5.4.1. Atuação judicial colaborativa, pautada por uma visão holística da saúde humana e do

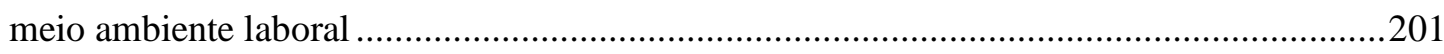

5.4.2. Primazia das tutelas jurisdicionais de caráter coletivo e de cunho preventivo-inibitório ......212

5.5. Prevenção e promoção da saúde mental do trabalhador: um desafio interinstitucional para as próximas décadas 


\section{INTRODUÇÃO}

O tema geral desta pesquisa diz respeito à proteção e promoção do direito fundamental à saúde mental dos trabalhadores, inserto na linha de pesquisa relacionada à tutela das projeções da personalidade humana no bojo das relações de trabalho (FADUSP).

O que despertou nosso interesse para o assunto foi a constatação de uma forte modificação na natureza das demandas apresentadas ao Judiciário Trabalhista, no decorrer da última década. As outrora numerosas denúncias envolvendo a ocorrência de acidentes típicos (amputações, traumatismos, intoxicações químicas, perdas auditivas induzidas por ruído, dermatites de contato, dentre outras), foram sendo paulatinamente substituídas por pedidos indenizatórios e de reintegração ao emprego envolvendo patologias de sobrecarga como as LER/DORT, transtornos mentais e comportamentais relacionados ao trabalho (TMCRT), doenças de fundo psicossomático, denúncias de assédio moral, straining, Síndrome de Burnout, Transtorno de Estresse Pós-Traumático (TEPT), Birôla (morte súbita de trabalhadores nos canaviais paulistas, por excesso de trabalho), além dos dramáticos casos de suicídios relacionados ao trabalho. Essa migração do mal-estar e sofrimento, que antes acometia os corpos físicos dos trabalhadores, para a esfera de suas mentes e psiquismo, além de indicar a baixa efetividade do direito fundamental objeto deste estudo, fez surgir profundo inquietamento sobre algumas questões: $i$ ) - será que essas morbidades psíquicas e psicossomáticas já existiam, nessa proporção, e apenas permaneciam alheias ao crivo do Judiciário por falta de iniciativa das partes, ou estaríamos presenciando fenômenos "novos", despertados por metamorfoses no mundo do trabalho ou na realidade sócio-econômica subjacente? ii) Seria esse um fenômeno tipicamente nacional ou algo também verificável em outros países e continentes? iii) - Tratar-se-ia de uma tendência irreversível, natural à própria evolução do sistema econômico vigente e correlatas formas de organização produtiva, ou haveria possibilidade de modificação desse cenário de morbidade acentuada? iv) - Em caso afirmativo, como proceder para assegurar maior respeito à jusfundamentalidade da incolumidade psíquica obreira? Em que esfera de intervenção poderiam ser encontrados os meios para atenuar o problema? Haveria registro de experiências exitosas, nessa área, em outros ordenamentos jurídicos? $v$ ) - De modo mais específico, qual seria o papel do Judiciário nesse cenário, consideradas as limitações decorrentes da imperiosa adstrição cognitiva judicial aos limites do pedido deduzido? Até 
que ponto a atividade jurisdicional poderia assumir cunho prevencionista, em relação à tutela da higidez labor-ambiental?

São todas perguntas complexas, multifacetadas e multidisciplinares, que exigiram respostas elaboradas com base em diversos ramos do conhecimento, de um modo transdisciplinar, visando suprir o notório déficit de reflexão que existe em relação ao tema, no campo do Direito. No vácuo desta lacuna científica é que a presente pesquisa presente atuar, tendo por objetivos específicos: i) - compreender os paradoxos do trabalho contemporâneo, que mesmo depois de ter incorporado elevados patamares tecnológicos, desde a $1^{a}$ Revolução Industrial, permanece provocando precarização objetiva e subjetiva para quem o exerce; ii) - delinear os contornos do que possa ser considerado "normal" ou "patológico", em termos de saúde mental relacionada ao trabalho; iii) - analisar as bases fundamentais técnico-jurídicas do direito à saúde mental do trabalhador brasileiro, procurando entender se a crise de efetividade desse direito decorre de insuficiência do respectivo arcabouço normativo ou se seriam outras as razões do problema; iv) compreender se e como a qualidade do meio ambiente de trabalho pode afetar a saúde mental do trabalhador, e se existe alguma dimensão dessa ambiência mais acentuadamente relacionada a essa afetação; v) - verificar em qual extensão a malha principiológica já construída pelo Direito Ambiental poderia ter aplicabilidade ao meio ambiente do trabalho e, em qual momento essa aplicação poderia ser operacionalizada e dirigida para o efetivo resguardo da saúde mental dos trabalhadores; vi) - analisar se há entraves técnicoburocráticos, jurídicos ou políticos para a implementação de um maior grau de proteção ao direito fundamental da saúde mental do trabalhador, e que tipo de modificações esses percalços estariam a desafiar, na contemporaneidade.

Procurou-se, em suma, analisar qual seja o atual estágio de efetividade do direito fundamental à saúde mental do trabalhador e oferecer novos parâmetros para ações que possam ampliar esse patamar protetivo nacional. Adotou-se como referencial teórico os ensinamentos da Psicodinâmica do Trabalho (PDT), também chamada escola dejouriana, cujos pressupostos foram considerados aptos a promover melhor compreensão dos vínculos potencialmente existentes entre as novas dinâmicas produtivas, o espraiamento de desequilíbrios psicossociais labor-ambientais e a eclosão ou agravamento de transtornos mentais e comportamentais nos trabalhadores a eles expostos.

Para atingir os fins propostos, a dissertação vem estruturada em cinco capítulos, sistematicamente conectados. 
O primeiro deles aborda a dialeticidade do fenômeno do trabalho, buscando compreender suas diversas dimensões ônticas e respectiva dialeticidade. Foram analisadas as metamorfoses ocorridas no mundo da produção capitalista, desde a década de 1970, buscando compreender como os sucessivos métodos adotados para a organização do trabalho (fordismo/taylorismo, toyotismo) e seus correlatos ideários afetaram a qualidade dos vínculos laborativos e que repercussões isso trouxe para a saúde mental dos trabalhadores. Serão apresentados dados estatísticos nacionais e internacionais relacionados tema e abordadas as consequências diretas e indiretas do adoecimento mental relacionado ao trabalho, para os indivíduos e para a sociedade.

O segundo capítulo enfatiza a evolução dos conceitos de saúde, saúde mental e saúde mental do trabalhador (esta última em perspectiva biopsicossocial), relacionando estudos interdisciplinares sobre o tema. Apresenta-se o panorama atual do arcabouço normativo de proteção ao direito humano fundamental em estudo, em seus aspectos individuais e transindividuais, compreendendo normas de direito e normas técnicas aplicáveis ao tema. A hipótese levantada, ao fim, é a de que, diante da relativa insuficiência desse arcabouço, a aplicação de alguns dos postulados clássicos de direito ambiental (notadamente os da prevenção/precaução), na gestão da saúde e segurança relacionada ao trabalho (SST) e no proferimento das decisões judiciais, pode colaborar para a preservação da higidez psicossocial labor-ambiental e para a promoção da saúde mental e qualidade de vida dos trabalhadores.

No terceiro capítulo são analisadas as diversas dimensões do meio ambiente do trabalho, apresentando-se a proposição de que, em uma compreensão holística (ou gestáltica), nele existe uma específica dimensão psicossocial, representada por aspectos imateriais ou relacionais, no bojo da qual encontram-se os "emergentes" riscos psicossociais labor-ambientais (RPSLA), já bastante estudados pela Psicologia da Saúde Ocupacional (PSO), mas ainda um enigma para a ciência do direito. A hipótese levantada é a de que a presença exacerbada desses riscos tenha potencial para produzir desequilíbrio sistêmico (ou endêmico) no meio ambiente de trabalho que, a depender do grau, induz o espraiamento de doenças psíquicas, psicossomáticas e agravos mentais dos mais diversos tipos, para os trabalhadores a eles expostos. $\mathrm{Na}$ ampliação desse desequilíbrio, podem surgir fenômenos profundamente negativos para todo o coletivo de trabalho, tendo sido estudadas duas situações eleitas representativas dessa afetação sistêmica: o assédio moral organizacional e a síndrome loco-neurótica (SLN). 
O quarto capítulo busca compreender como ocorre a evolução, desde a etapa prépatológica, do "sofrimento" no trabalho (tomada essa expressão segundo concepção da Psicodinâmica do Trabalho, em suas diversas formas e desdobramentos), até a fase em que efetivamente desenvolvidas doenças psicossomáticas ou transtornos mentais e comportamentais relacionados ao trabalho. Para exemplificar essas conexões, são analisados os resultados de três estudos empíricos desenvolvidos à luz do referencial teórico dejouriano, levados a cabo junto a distintos coletivos de trabalho (magistrados brasileiros, jornalistas e funcionários de uma empresa francesa com alta epidemiologia suicidária), cujas conclusões corroboram a possibilidade de eclosão de variadas descompensações fisiopsíquicas, a depender das amplitude das fragilidades organizacionais subjacentes ao evento, das predisposições psicofísicas individuais e das circunstâncias de elaboração do sofrimento individual e coletivo.

O quinto e último capítulo propõe que a redução progressiva dos RPSLA, realizada mediante estratégias pautadas pelos princípios da melhoria contínua e da eliminação dos riscos na fonte, tem potencial para prevenir e promover o direito fundamental à saúde mental do trabalhador. São investigados alguns problemas nacionais contemporâneos considerados elementares para a configuração da atual crise de efetividade desse direito e quais desafios interinstitucionais ainda demandam superação, para que saúde mental, higidez psicossocial labor-ambiental e qualidade de vida ocupacional possam vir a ser, mais do que abstratas previsões do ordenamento jurídico, reais possibilidades em nosso País. Sugere-se a necessidade de ruptura com o paradigma vigente, centrado na doença e nas disfuncionalidades (patogênico), rumo a uma atuação salutogênica, i.e., focada na saúde biopsicossocial e que procure alcançar a máxima performance dos indivíduos e das organizações de trabalho. Para tal desiderato, leva-se em conta o caminho sugerido pela OMS para a manutenção de ambientes de trabalho saudáveis, com ênfase na recomendação de atenção "integral e integrada" às necessidades dos trabalhadores, convocados a forte protagonismo na gestão da Saúde e Segurança no Trabalho (SST), com destaque para a obrigatoriedade de as intervenções prevencionistas-precaucionárias serem levadas a efeito em três níveis de ação junto ao microssistema ambiental organizacional (primário, secundário e terciário), sob pena de sua ineficácia.

Ao fim, são apresentadas as conclusões gerais extraídas da pesquisa.

Diante da amplitude do tema e da multidisciplinaridade a ele inerente, a pesquisa teórica empregou dados de revisão bibliográfica com base histórica e contemporânea. A 
demonstração das hipóteses formuladas foi alcançada pelo método dedutivo, a partir de reflexão interpretativa dos dados colhidos. Foram exploradas as seguintes fontes de pesquisa: livros, ementários, periódicos, edições eletrônicas, sítios virtuais de Tribunais, edições legais, inclusive comentadas, notícias de jornais e periódicos, nas seguintes áreas de conhecimento: Direito do Trabalho e Processual do Trabalho, Direito Ambiental, Economia, Sociologia, Psicologia do Trabalho, Psiquiatria, Psicanálise, Ergonomia e Saúde Ocupacional. A escassez doutrinária e jurisprudencial nacional a respeito de alguns aspectos do tema exigiu a consulta de autores e legislação estrangeiros, conforme registrado nas referências bibliográficas listadas ao fim do trabalho. Foram também empreendidas buscas de materiais de referência em bases de dados de bibliotecas eletrônicas relacionadas às áreas de conhecimento anteriormente elencadas, especialmente o Portal DEDALUS da USP e suas bibliotecas; a Scientific Eletronic Library Online SciElo; a BVS - Biblioteca Virtual em Saúde e o Portal de Periódicos da Capes (Coordenação de Aperfeiçoamento de Pessoal de Nível Superior), dentre outras. Índices estatísticos e informações diversas foram obtidos junto a Tribunais, Associações, Organismos Internacionais (ONU, OIT, OMS, OEA, EU-OSHA, NIOSH), além de trabalhos científicos divulgados por órgãos como CESIT, INSS, FUNDACENTRO. Os resultados respectivos foram dispostos em tabelas, para auxiliar a interpretação dos fenômenos por eles apontados. 


\section{CONSIDERAÇÕES FINAIS}

Enfrentamos tempos de tecnologias disruptivas, que impõem novas formas de trabalhar e diversos modos de sofrer. A modernização dos sistemas produtivos trouxe conforto ergonômico para alguns tipos de trabalho mas, paradoxalmente, também fez com que, em certos tipos de atividade, o sofrimento do corpo fosse transmudado em agruras para o psiquismo (algo mais cruel, porque menos visível e dificilmente mensurável de forma objetiva), mas que opera de forma igualmente intensa e prejudicial à saúde transindividual dos trabalhadores.

A globalização econômica, ao impor competitividade empresarial acirrada, exige dos trabalhadores cada vez maior produtividade e perfeição técnica, além de um forte engajamento subjetivo aos objetivos empresariais. A necessidade de alcançar o menor custo de produção conduz ao corte de gastos e enseja dispensa massiva; a produção se desenvolve com quadro de pessoal cada vez mais reduzido e precarizado; há diminuição de empregabilidade, concorrência interpessoal acirrada, queda geral de rendimentos. Entram em cena trabalhadores informais, temporários, part-time, pseudocooperados, pejotizados, uberizados, teleworkers e tantos outros precarizados. Banaliza-se a gestão por estresse, que incrementa os ritmos e a pressão de tempo, impõe longas jornadas, monotonia de tarefas, conflitos de papéis e baixo poder de decisão. A atividade realizada em meio aos constrangimentos de uma organização do trabalho que não cede espaço à invenção, criatividade e auto-expressão individual, torna "normopáticos" os trabalhadores - ainda não doentes, mas espécies de mortos-vivos, zumbis à mercê de um processo produtivo que não respeita seus limites psicofísicos. Tornam-se insensíveis ao sofrimento próprio e alheio para não ter que suportar, conscientemente, as agruras de ambientes neurotizantes, rotinas estafantes, chefias abusivas e desrespeitosas. Recorrem a soníferos, calmantes, psicoestimulantes (legais e ilegais), a todo tipo de recurso químico, enfim, que prometa alguma dose de felicidade instantânea ou amortização ao sofrimento e desgaste acentuado. Para "tolerar o intolerável", criam estratégias defensivas (individuais e coletivas), até o ponto em que seja possível essa esquiva. Essa é, segundo a teoria dejouriana, a etapa do "sofrimento", correspondente ao campo do pré-patológico. Sem que haja uma adequada elaboração de estratégias defensivas individuais ou coletivas e, restando superado o limite biopsicofisiológico de tolerância individual ao fator específico de agressividade laboral, 
existe a possibilidade de transbordamento de grau, adentrando-se o campo do patológico, propriamente dito.

Esse complexo cenário sócio-econômico da atual etapa da modernidade impõe uma nova compreensão do fenômeno saúde ocupacional e uma nova interpretação para a configuração do meio ambiente de trabalho e suas múltiplas confluências.

Resta claramente ultrapassada a concepção "unicausal" do adoecimento mental; a particular etiologia dos agravos mentais relacionados ao trabalho exige estudo multifatorial dos agentes deflagradores das enfermidades, devendo ser levados em conta os determinantes sociais e as questões subjetivas relacionadas ao exercício laboral, agrupados em quatro grandes categorias: estilo de vida, ambiente, organização dos cuidados à saúde e biologia humana. As investigações relacionadas à higidez mental ocupacional devem sempre levar em conta a multidimensionalidade do ser (biológica, social, histórica), com ênfase nos aspectos relacionados à Gestalt labor-ambiental, a cujas confluências o indivíduo permanece exposto durante pelo menos um terço de sua vida útil.

Uma visão sistêmica e dinâmica do habitat laboral exige nele vislumbrar uma dimensão imaterial, psicológica ou relacional (dimensão psicossocial), no seio da qual encontram-se fatores de risco ditos "emergentes" (os riscos psicossociais labor-ambientais - RPSLA), ainda uma novidade para o mundo do Direito do Trabalho, mas já bastante estudados em outras áreas do conhecimento. Esses riscos envolvem circunstâncias relacionadas às próprias condições de desenvolvimento laborativo, à forma de organização do trabalho e à qualidade das interações socioprofissionais, elementos que, unidos, formam uma constelação passível de provocar desequilíbrio sistêmico, tornando adversas as características do meio ambiente laboral para a saúde dos trabalhadores. A hipótese que restou confirmada neste estudo é a de que essa forma de degradação da dimensão psicossocial labor-ambiental não constitui um fenômeno irreversível, ao qual cabe o trabalhador simplesmente se submeter, passivamente. Tal qual ocorre com os tradicionais fatores de risco, é possível promover adequada identificação e mensuração dos RPSLA, com sua inclusão no mapa geral de riscos, além de sua oportuna consideração nas estratégias preventivas e corretivas organizacionais, mediante sua adequada abordagem e manejo por meio de ferramentas apropriadas.

Considera-se demonstrada, ademais, a importância de incorporar uma visão prevencionista-precaucionária em relação a esses riscos psicossociais, guiada por uma atuação integral e integrada de órgãos governamentais e outros interlocutores sociais na 
conquista de saúde mental e qualidade de vida no trabalho, num continuum que pode beneficiar a todos: indivíduo, organizações, Estado e sociedade. Essa forma de atuação tem respaldo no modelo concebido pela Organização Mundial de Saúde para conquista de ambientes saudáveis. Fala-se em atuação “integral”, porque deve contemplar os vários aspectos envolvidos na atividade profissional, abrangendo o ambiente físico (material) e o psicossocial, além dos recursos para a saúde pessoal, levando em conta as múltiplas dimensões da saúde: física, emocional, social, profissional; é uma atuação "integrada", porque envolve interação entre vários atores sociais, englobando as equipes de segurança e de saúde (SESMT), os setores de recursos humanos, a equipe de produção, as equipes jurídicas, sindicatos e outros setores da organização social, criando uma verdadeira cultura voltada à prevenção dos ambientes de trabalho saudáveis. Essa ações integrais e integradas devem ser baseadas em forte interinstitucionalidade e acentuado protagonismo dos próprios trabalhadores no processo de identificar e compreender como interagem os fatores que favorecem o adoecimento relacionado ao trabalho, o que implica sair da periferia do problema para atuar em suas verdadeiras causas, i.e., abandonar o tradicional paradigma patogênico (focado na medicamentalização da vida e na correção dos danos, depois de consumados), rumo à adoção de uma atitude salutogênica, que evite os problemas de saúde quando isso ainda seja possível e que promova qualidade de vida no trabalho.

Para que essa atuação integral e integrada, promotora e prevencionista da saúde mental ocupacional seja uma realidade no Brasil, muito ainda é preciso evoluir. O estudo destaca diversos fatores considerados entraves à conquista da SMRT plena, dentre os quais, a obsolescência e insuficiência do arcabouço protecionista nacional, uma cultura disseminada de estigmatização dos portadores de psicopatologias relacionadas ao trabalho, a ineficácia do aparato governamental fiscalizatório às infrações patronais, uma preferência cultural pela monetização dos agravos e danos já consumados. Para que esses problemas sejam superados, muito há a fazer.

O tratamento das questões relacionadas ao bem-estar dos trabalhadores no local de trabalho precisa evoluir significativamente, de um mero cipoal desconexo de normas parcialmente protetivas - esparsas e insuficientes a uma proteção integral - para uma formulação mais coerente, dotada de organicidade e integração, que constitua propriamente um microssistema jurídico, subordinado ao bem da vida constitucionalmente tutelado nas regras do artigo $6^{\circ}$, artigo $7^{\circ}$, inc. XXII, artigo 200 , inc. VIII e artigo 225 , todos da Lei Maior. Reputa-se urgentemente necessária uma regulamentação legal dotada de 
organicidade e coerência, e que, a exemplo do quanto já realizado em relação aos tradicionais riscos físicos, químicos, biológicos, ergonômicos e acidentários, estabeleçam parâmetros para o reconhecimento, avaliação e controle dos riscos psicossociais ocupacionais, com ênfase na questão da organização do trabalho, para que seja ela adaptada ao homem (e não o contrário, como tem ocorrido na prática), com a determinação de práticas que preservem a saúde do trabalhador em sua inteireza, i.e., em sua dimensão biopsicossocial.

Também urge que sejam editadas políticas públicas específicas quanto ao tema, eis que as existentes, além de serem voltadas à saúde em geral (e não à saúde mental dos trabalhadores) consubstanciam algo mais próximo de um "protocolo de intenções", composto por previsões abstratas e desprovidas de força cogente para incentivar os empresários à adoção de medidas concretas de prevenção e precaução ao adoecimento mental. Devem ser implementadas novas práticas governamentais e patronais, guiadas pelo paradigma salutogênico, que prestigiem a investigação, reconhecimento e manejo dos múltiplos fatores determinantes do adoecimento, que difunda gradativamente nova cultura entre os profissionais envolvidos na questão da Saúde e Segurança do Trabalho, envolvendo um treino interdisciplinar e transversalizante, compreendendo diversas áreas do saber, como as da Psicologia da Saúde Organizacional (PSO), da Saúde Mental Relacionada ao Trabalho (SMRT) e da Psicodinâmica do Trabalho (PDT ou escola dejouriana), tratados no decorrer desta pesquisa. Precisam ser formuladas e implantadas medidas preventivas e de disseminação de informações sobre boas práticas nos ambientes de trabalho e para além deles, criando-se uma rede ampla em vigilância à saúde mental do trabalhador.

Entendemos ter também demonstrado que a sugerida implementação de melhorias labor-ambientais pode alcançar maior eficácia se for guiada pela aplicação da malha principiológica do Direito Ambiental (com ênfase nos princípios da informação, colaboração, transdisciplinaridade, prevenção e precaução), realizada em níveis progressivos de intervenção no coletivo de trabalho (primária, secundária, terciária) e que permita a incorporação do mais avançado estado da técnica haurido em cada ramo do conhecimento (princípio da melhoria contínua), tudo direcionado à busca de um patamar protetivo mais efetivo e eficaz à jusfundamentalidade da saúde mental do trabalhador. Imperioso que se conheça a fundo a organização do trabalho, para poder transformá-la positivamente e para construir o saber operário por meio de informação, diálogo, 
treinamento e participação ativa de trabalhadores e seus sindicatos, a fim de que também se assumam protagonistas desse processo de construção da melhoria contínua laborambiental.

Embora não seja possível reverter os efeitos da tendência crescente à superexploração do trabalho humano na atual etapa do capitalismo predatório, certo é que adoecimento mental e sofrimento não podem continuar a ser vistos como simples "danos colaterais" dos processos de produção. Normalizar o sofrimento e aviltar a dignidade do trabalhador em nome da competitividade e lucro empresarial são formas intoleráveis de banalização do mal. A obsolescência programada de produtos não pode ser transposta para os seres humanos. Aposentação precoce, adoecimento e descartabilidade daqueles que, depois de maltratrados pelas agruras de um trabalho realizado sem respeito aos limites psicofísicos da "máquina" humana, passam a ser considerados redundantes ao processo produtivo, é um fenômeno cruel e que impõe pesado fardo sobre toda a sociedade, em razão dos custos diretos e indiretos da epidemiologia dos adoecimentos, expostos minudentemente neste estudo.

É preciso compreender que não existe desenvolvimento sustentável sem respeito aos direitos humanos fundamentais. A saúde mental do trabalhador, enquanto fração dessa jusfundamentalidade, é dotada de irrenunciabilidade e deve ser protegida e promovida em suas diversas dimensões, i.e, enquanto direito individual de manutenção da saúde no trabalho, pelo trabalho e para o trabalho, de modo a assegurar não apenas o direito à conservação do grau de saúde mental já conquistado, mas também o de ir sempre adiante, rumo à autorrealização profissional, crescimento pessoal e consecução dos projetos existenciais individualmente eleitos, mantidos a salvo de intercorrências acidentárias ou adoecedoras. Como assegurar efetividade a esse desiderato constitui enorme desafio contemporâneo para juristas e demais profissionais envolvidos com o tema da Saúde Mental Relacionada ao Trabalho.

Entende-se necessário um novo olhar do Judiciário para a regulação jurídica das relações entre capital e trabalho. É chegado o tempo de, em vez de lamuriar a incompletude e insuficiência do arcabouço jurídico-normativo em relação ao tema, ao confrontar-se o magistrado com tal deficiência, buscar extrair o melhor resultado possível em matéria de proteção à dignidade do ser humano trabalhador, afastando-se do improfícuo conservadorismo hermenêutico e recorrendo, quando necessário, aos princípios gerais de direito e aos princípios específicos do Direito do Trabalho e do Direito Ambiental 
(dentre outros), guiando-se pela bússola dos juízos valorativos que prestigiem a máxima eficácia dos preceitos constitucionais e alcancem justiça social e bem estar a quem clama pela tutela jurisdicional, prestigiando, sempre que possível, as medidas de caráter coletivo e de cunho preventivo-inibitório, tendencialmente mais favoráveis à proteção do meio ambiente de trabalho saudável e isento de riscos, com benefício para as presentes e futuras gerações de trabalhadores.

É preciso, em suma, reconhecer a essencialidade e centralidade do trabalho na vida social e na busca da autorrealização pessoal, para que a sentença insculpida em ferro sobre os portões de Auschwitz (arbeit macht frei - o trabalho liberta) jamais soe como nefasta ironia, a pesar sobre os ombros de quem, ao fim e ao cabo, apenas encontra no trabalho fonte de sofrimento, dor e morte. Por meio do labor digno e saudável, equilibrante e vitalizador, deve haver a oportunidade de conquista de efetivo processo emancipatório individual, o que significa "honrar a vida" em toda a sua multidimensionalidade.

Lutar pelo meio ambiente de trabalho seguro e saudável significa, sobretudo, dar cumprimento ao princípio n.1 da Declaração-1992 do Rio de Janeiro, segundo o qual “os seres humanos devem estar no centro da preocupação para com o desenvolvimento sustentável", assim como ao mandamento contido na regra do artigo 225 da CRFB, que impõe ao Poder Público e à coletividade, o dever de defender e preservar o meio ambiente ecologicamente equilibrado "para as presentes e futuras gerações". A palavra de ordem deve ser o respeito máximo à dignidade da pessoa humana, núcleo irredutível de toda a ordem jurídica. Somente um esforço prevencionista e precaucionário conjugado, com adoção de ações nos campos político, jurídico e social, guiadas por interinstitucionalidade, transdisciplinaridade e pelos princípios de direito destacados nesta pesquisa permitirá algum dia dizer que, em nossa nação, o trabalho deixou de ser fonte de adoecimento, loucura e morte. 


\section{REFERÊNCIAS}

AGÊNCIA EUROPEIA PARA A SEGURANÇA E SAÚDE NO TRABALHO. Directivaquadro relativa à SST. Disponível em: <http://osha.europa.eu/pt/legislation/directives/the-oshframework-directive/the-osh-framework-directive-introduction>. Acesso em: 03 maio 2017.

- Previsão dos peritos sobre os riscos psicossociais emergentes relacionados com a segurança e saúde no trabalho (SST): FACTS 74 PT. 2007. Disponível em: <http://osha.europa.eu>. Acesso em: 01 nov. 2017.

ALEVATO, Hilda Maria Rodrigues. Estilos de gestão de pessoas e sofrimento psíquico: a importância da sociodinâmica do trabalho. In: FELICIANO, Guilherme Guimarães et al (Orgs.). Direito ambiental do trabalho: apontamentos para uma teoria geral. São Paulo: LTr, 2015. v. 2.

- Trabalho e neurose: enfrentando a tortura de um ambiente em crise. Rio de Janeiro: Quartet, 1999.

ALEXY, Robert. Teoria dos direitos fundamentais. 2. ed. 3. tir. São Paulo: Malheiros Ed., 2014.

ALMEIDA, Victor Hugo de. Meio ambiente do trabalho e saúde mental do trabalhador sob a perspectiva labor-ambiental. In: RAZZOUK, Denise; LIMA, Mauro Gomes Aranha de; CORDEIRO, Quirino (Orgs.). Saúde mental e trabalho. São Paulo: Conselho Regional de Medicina do Estado de São Paulo - Cremesp, 2015.

ALVES, Giovanni. Precarização do trabalho, qualidade de vida e saúde dos magistrados trabalhistas no Brasil. Revista do Tribunal Regional do Trabalho da 15 Região, Campinas, n. 47, p.243-258, jul. 2015.

Produção do Capital e a degradação da pessoa humana: notas críticas sobre a barbárie social e a precarização do homem-que-trabalha. In: VIZZACCARO-AMARAL, André Luís; MOTA, Daniel Pestana; ALVES, Giovanni (Orgs.). Trabalho $e$ estranhamento: saúde e precarização do homem-que-trabalha. São Paulo: LTr, 2012.

AMERICAN PSYCHIATRIC ASSOCIATION. Manual diagnóstico e estatístico de transtornos mentais: DSM-5. 5. ed. Porto Alegre: Artmed, 2004. 948 p.

ANDALUCIA. Departamento de Asistencia Técnica para la Prevención de Riesgos Laborales - UGT. Guía de prevención de riesgos psicossociales en el trabajo. Andalucia: Fundación para la Prevención de Riesgos Laborales, 2010. 115 p.

Ley $\mathrm{n}^{\mathrm{o}}$ 31/1995, de 08 de novembro de 1995. Ley de Prevención de Riesgos Laborales. Gobierno de España: Instituto Nacional de Seguridad e Higiene en el Trabajo, 10 nov. $1995 . \quad$ Disponível em: <www.insht.es/InshtWeb/Contenidos/Normativa/TextosLegales/LeyPrevencion/PDFs/leyd eprevencionderiesgoslaborales.pdf>. Acesso em: 03 jan. 2018. 
ANTUNES, Ricardo. O caracol e sua concha: ensaios sobre a nova morfologia do trabalho. São Paulo: Boitempo, 2005. 136 p.

; DRUCK, Graça. A epidemia da terceirização. In: ANTUNES, Ricardo (Org.). Riqueza e miséria do Trabalho no Brasil. São Paulo: Boitempo, 2014. (Col. Mundo do Trabalho - v. 3).

; PRAUN, Luci. A sociedade dos adoecimentos no trabalho. Serviço Social, São Paulo, v. 123, p.407-427, set. 2015.

AREOSA, João. Comentário ao artigo 'a sublimação, entre sofrimento e prazer no trabalho" - Christophe Dejours e a psicodinâmica do trabalho. Revista Portuguesa de Psicanálise, v. 33, n. 2, p.29-41, ago. 2013. Disponível em: $<$ https://repositorium.sdum.uminho.pt/bitstream/1822/26902/1/Christophe\%20Dejours\%20 e\%20a\%20Psicodin\%C3\%A2mica\%20do\%20Trabalho.pdf>. Acesso em: 01 nov. 2017.

; VELOSO NETO, Hernâni. Sociedade dos riscos emergentes. In: VELOSO NETO, Hernâni; AREOSA, João; AREZES, Pedro (Eds.). Manual sobre riscos psicossociais no trabalho. Porto: Varzea da Rainha Impressores, Sa, 2014. Cap. 1. p. 5-23. (Coleção RICOT - Rede de Investigação sobre Condições de Trabalho - Instituto de Sociologia da Universidade do Porto).

ARTUR, Karen. Saúde do trabalhador: desafios da institucionalização de um direito humano. In: FELICIANO, Guilherme Guimarães et al. (Coords.). Direito ambiental do trabalho: apontamentos para uma teoria geral. São Paulo: LTr, 2015. v. 2, Cap. 3. p. 55-62.

ASSOCIAÇÃO NACIONAL DOS MAGISTRADOS DA JUSTIÇA DO TRABALHO (ANAMATRA). $18^{\circ}$ CONAMAT Salvador/BA. ANAMATRA 40 anos: Magistratura, Independência e Direitos Sociais. 27-30 abr. 2016. Disponível em: <http://www.conamat.com.br/listagem-teses-aprovado.asp>. Acesso em: 30 abr. 2016.

AUTORIDADE PARA AS CONDIÇÕES DE TRABALHO - ACT. Campanha de Segurança e Saúde no Trabalho da Condução Automóvel Profissional. 2015. Disponível em:

<http://www.acisb.pt/pt/images/MANUAL_SST_CONDUÇÃO_AUTOMÓVEL_PROFIS SIONAL_FINAL.pdf>. Acesso em: 12 maio 2017.

BARRETO, Margarida Maria Silveira; HELOANI, José Roberto. As doenças psicossomáticas decorrentes do ambiente de trabalho: prevenção e boas práticas. In: DEVONALD, Silvia Regina Pondé Galvão; NAHAS, Thereza Christina (Coords.). Desafios para alcançar o trabalho seguro no Brasil: um estudo das situações adversas à relação de trabalho. São Paulo: LTr, 2015. Cap. 5. p. 49-56.

Violência, saúde e trabalho: a intolerância e o assédio moral nas relações laborais. Serviço Social e Sociedade, São Paulo, n. 123, p.1-10, 01 set. 2015. Disponível em: $\quad<h t t p: \| w w w . s c i e l o . b r . p h p ? s c r i p t=s c i \_a r t t e x t \& p i d=S 0101$ 6628201500003000544\&Ing>. Acesso em: 14 jan. 2017. 
BARROS, Juliana de Oliveira. Interfaces entre produção de saúde e coordenação do cuidado: perspectiva da psicodinâmica do trabalho na compreensão do trabalhar de médicos inseridos em um hospital universitário. 2015. 242 f. Tese (Doutorado) - Curso de Medicina, Ciências da Reabilitação, Universidade de São Paulo, São Paulo, 2015.

BARUKI, Luciana Veloso. Riscos psicossociais e saúde mental do trabalhador: por um regime jurídico preventivo. São Paulo: LTr, 2015.

BEAUDONNET, Xavier (Ed.). Direito internacional do trabalho e direito interno: manual de formação para juízes, juristas e docentes em direito. Colaboradores Xavier Beaudonnet, International Training Centre of the ILO. Tradução de Sieni Campos Traduções. Brasília: ANAMATRA/ALJT, 2011.

BERNARDO, Marcia Hespanhol; GARBIN, Andréia de Conto. A atenção à saúde mental relacionada ao trabalho no SUS: desafios e possibilidades. Revista Brasileira de Saúde Ocupacional, São Paulo, v. 36, n. 123, p.103-117, 2011.

BERTOLINO, Osvaldo. A crise do Fordismo [2015]. RET - Rede Estudos do Trabalho. Disponível em: <www.estudosdotrabalho.org/artigo-osvaldo-bertolino-crisefordismo.pdf >. Acesso em: 19 jun. 2016.

BIT - BUREAU INTERNACIONAL DO TRABALHO. Riscos emergentes e novas formas de prevenção num mundo do trabalho em mudança. Genebra: Palmigráfica Artes Gráficas, 2010. 17 p. Disponível em: 〈http://ilo.org/lisbon〉. Acesso em: 11 jan. 2017.

Ministério da Saúde do Brasil. Organização Pan-Americana da Saúde do Brasil. Doenças relacionadas ao trabalho: manual de procedimentos para os serviços de saúde. Org. por Elizabeth Costa Dias; colaboradores Idelberto Muniz Almeida et al. Brasília: Ministério da Saúde do Brasil, 2001. 580 p. 580 p. (Série A. Normas e Manuais Técnicos; n.114). Disponível em: <http://bvsms.saude.gov.br/bvs/publicacoes/doencas_relacionadas_trabalho1.pdf>.

Tribunal Superior do Trabalho. Escola Nacional de Formação e Aperfeiçoamento de Magistrados do Trabalho (ENAMAT). Curso de Formação Continuada (CFC). Prova Pericial em Acidentes e Doenças Ocupacionais. Modalidade de educação à distância. Brasília, 2015.

Tribunal Superior do Trabalho. Escola Nacional de Formação e Aperfeiçoamento de Magistrados do Trabalho (ENAMAT). Propostas de Enunciados e Diretrizes sobre perícias judiciais em acidente do trabalho e doenças ocupacionais. 2013. Comissão Trabalho Seguro - Programa Nacional de Prevenção de Acidentes de Trabalho. Disponível em: <http://www.enamat.jus.br/?page_id=9717>. Acesso em: 15 fev. 2015.

BUTIERRES, Maria Cecília. O direito à saúde do trabalhador e a Convenção 187 da OIT: elementos para uma transição de paradigmas na prevenção. 2015. 148 f. Dissertação (Mestrado) - Programa de Pós-Graduação em Direito, Universidade Federal do Rio Grande do Sul, Porto Alegre, 2015. Disponível em: <http://www.lume.ufrgs.br/bitstream/handle/10183/121897/000970811.pdf?sequence=1>. Acesso em: 23 jan. 2017. 
CABRAL, Angelo Antonio. Direito ambiental do trabalho na sociedade do risco. Curitiba: Juruá, 2016. 224 p.

CAMACHO, Sebastián Segura. Normatividad Colombiana de Riesgos Psicosociales. 2015. Disponível em: <http:www.prax.com.co/2015/11/09/normatividade-colombiana-deriesgos-psicosociales/>. Acesso em: 09 nov. 2015.

CAMARGO, Duílio Antero de; CAETANO, Dorgival; GUIMARÃES, Liliana Andolpho Magalhães (Orgs.). Psiquiatria ocupacional: aspectos conceituais, diagnósticos e periciais dos transtornos mentais e do comportamento relacionados ao trabalho. São Paulo: Atheneu, 2010.

CANADA. Bureau de Normalisation du Québec - BNQ. Commissioned by the Mental Health Commission of Canada. Psychological health and safety in the workplace: prevention, promotion and guidance to staged implementation. 2013. Editado por Mental Health Commission of Canada (MHCC). Disponível em: <http://www.csagroup.org/documents/codes-and-standards/publications/CAN_CSAZ1003-13_BNQ_9700-803_2013_EN.pdf>. Acesso em: 04 jan. 2018.

CATALDI, Maria José Gianella. Stress no meio ambiente do trabalho. 3. ed. São Paulo: LTr, 2015. 182 p.

CECCARELLI, Paulo. O sofrimento psíquico na perspectiva da psicopatologia fundamental. Psicologia em Estudo, Maringá, v. 10, n. 3, p.471-477, dez. 2015. Disponível em: 〈www.scielo.br/pdf/\%OD/pe/v10n3/v10n314.pdf〉. Acesso em: 28 jun. 2016.

CHRISTOPHE Dejours. Disponível em: <https://pt.wikipedia.org/wiki/Christophe_Dejours>. Acesso em: 26 jan. 2017.

CID10. Disponível em: <www.cid10.com.br>.

CONSELHO DAS COMUNIDADES EUROPEIAS - CCE. Diretiva $n^{\circ}$ 89/391, de 12 de junho de 1989. Relativa à aplicação de medidas destinadas a promover a melhoria da segurança e saúde dos trabalhadores. Directiva 89/391 - CCE. Luxemburgo, 11 dez. 2008. Disponível em: <http://eur-lex.europa.eu/legalcontent/PT/TXT/PDF/?uri=CELEX:01989L0391-20081211\&from=EN>. Acesso em: 04 jan. 2018.

CONSELHO NACIONAL DE JUSTIÇA - CNJ. Resolução nº 106, de 06 de abril de 2010. Disponível em: <http://www.cnj.jus.br///images/atos_normativos/resolucao/resolucao_106_06042010_111 02012191157.pdf>. Acesso em: 06 nov. 2017.

DEJOURS, Christophe. A banalização da injustiça social. Tradução de Luiz Alberto Monjardim. 7. ed. Rio de Janeiro: FGV, 2007. 160 p.

Da psicopatologia à psicodinâmica do trabalho. Orgs. Selma Lancman, Laerte Idal Sznelwar. 3. ed. Brasília: Paralelo 15, 2011. 512 p. 
DEJOURS, Christophe. O fator humano. Tradução Maria Irene Stocco Betiol, Maria José Tonelli.5. ed. Rio de Janeiro: FGV, 2005. 104 p.

. A loucura do trabalho: estudo de psicopatologia do trabalho. Tradução de Ana Isabel Paraguay e Lúcia Leal Ferreira. 5. ed. São Paulo: Cortez - Oboré, 1992. 168 p.

. Trabalho vivo: sexualidade e trabalho. Tradução de Franck Soudant. Brasília: Paralelo 15, 2012. v. 1. 216 p.

Trabalho vivo: trabalho e emancipação. Tradução de Franck Soudant. Brasília: Paralelo 15, 2012a. 222 p. v. 2.

; ABDOUCHELI, Elisabeth; JAYET, Christian. Psicodinâmica do trabalho: contribuições da Escola Dejouriana à análise da relação prazer, sofrimento e trabalho. 15. reimpr. São Paulo: Atlas, 2014. 145 p.

; BÈGUE, Florence. Suicídio e trabalho: o que fazer. Tradução de Franck Soudant. Brasília: Paralelo 15, 2010. 128 p.

; DESSORS, Dominique; DESRIAUX, François. Por um trabalho, fator de equilíbrio. Revista de Administração de Empresas, São Paulo, v. 3, n. 33, p.98-104, 30 jun. 1993. Disponível em: <www.scielo.br/pdf/rae/v33n3/a09v33n3>. Acesso em: 18 dez. 2016.

DELGADO, Maurício Godinho. Capitalismo, trabalho e emprego: entre o paradigma da destruição e os caminhos da reconstrução. 2. ed. São Paulo: LTr, 2015. 142 p.

DEPRESSÃO é tema de campanha da OMS para Dia Mundial da Saúde de 2017. Nações Unidas no Brasil, 19 dez. 2016. Disponível em: <https://nacoesunidas.org/depressao-etema-de-campanha-da-oms-para-dia-mundial-da-saude-de-2017/>. Acesso em: 03 jan. 2017.

DINIZ, Maria Helena. Compêndio de introdução à ciência do direito, 14. ed. São Paulo: Saraiva, 2001.

DI NUBILA, Heloisa B.V. Uma introdução à CIF: classificação internacional de funcionalidade, incapacidade e saúde. Revista Brasileira de Saúde Ocupacional, São Paulo, v. 35, n. 121, p.1-3, jun. 2010. Semestral. Disponível em: <http://www.scielo.br/pdf/rbso/v35n121/13.pdf>. Acesso em: 12 dez. 2016.

DRUCK, Graça. A precarização social do trabalho no Brasil: alguns indicadores. In: ANTUNES, Ricardo (Org.). Riqueza e miséria do trabalho no Brasil II. São Paulo: Boitempo, 2013.

EBERT, Paulo Roberto Lemgruber. A presunção juris tantum dos limites de tolerância fixados na NR -15: O caso emblemático do mercúrio. In: FELICIANO, Guilherme Guimarães et al. (Orgs.). Direito ambiental do trabalho: apontamentos para uma teoria geral. São Paulo: LTr, 2015. v. 2. 
EU-OSHA. Agência Europeia Para a Segurança e Saúde no Trabalho (Ed.). Legislação: Directiva-quadro 89/391/CEE. $1989 . \quad$ Disponível em: <https://osha.europa.eu/pt/legislation/directives/the-osh-framework-directive/the-oshframework-directive-introduction>. Acesso em: 03 jan. 2018.

FACAS, Emílio Peres. Protocolo de avaliação dos riscos psicossociais no trabalho: contribuições da psicodinâmica do trabalho. 2013. 191 f. Tese (Doutorado) - Curso de Psicologia Social, do Trabalho e das Organizações, Instituto de Psicologia, Universidade de Brasília, Brasília, 2013. Disponível em: $<$ http://repositorio.unb.br/bitstream/10482/15420/1/2013_EmilioPeresFacas.pdf >. Acesso em: 23 mar. 2017.

FANTAPPIÉ, Marcelo. Epigenética e memória celular. 2013. Disponível em: <http://revistacarbono.com/artigos/03-epigenetica-e-memoria-celular-marcelofantappie/>. Acesso em: 30 out. 2017.

FANTINI, Lorenzo. A regulamentação do estresse relacionado ao trabalho na Itália. In: FELICIANO, Guilherme Guimarães et al. (Orgs.). Direito ambiental do trabalho: apontamentos para uma teoria geral. São Paulo: LTr, 2015. v. 2.

FELICIANO, Guilherme Guimarães. Curso crítico de direito do trabalho: teoria geral do direito do trabalho. São Paulo: Saraiva, 2013. 298 p.

. O meio ambiente do trabalho e a responsabilidade civil patronal: reconhecendo a danosidade sistêmica. In: FELICIANO, Guilherme Guimarães; URIAS, João (Orgs.). Direito ambiental do trabalho: apontamentos para uma teoria geral. São Paulo: LTr, 2013. p. 11-25.

Tutela inibitória em matéria labor-ambiental. Revista do Tribunal Superior do Trabalho, Brasília, v. 77, n. 4, p.140-160, out./dez. 2011. Disponível em: <https://juslaboris.tst.jus.br/bitstream/handle/1939/28316/2011_rev_tst_v077_n004.pdf?se quence $=1 \&$ isAllowed=y $>$. Acesso em: 01 maio 2017 .

Tutela processual dos direitos humanos nas relações de trabalho. Evocati, [s.L.], v. 27, p.1-24, 17 mar. 2008. Disponível em: <http://www.evocati.com.br/evocati/artigos.wsp?tmp_codartigo=199>. Acesso em: 30 maio 2016.

FONSECA, Ricardo Tadeu Marques da. Assédio moral organizacional: o poder diretivo pode adoecer e causar feridas. In: GEDIEL, José Antonio Peres et al (Orgs.). Estado, poder e assédio: relações de trabalho na administração pública. Curitiba: Kairós, 2015. p. 31-51.

FONTES, Maria. Normopatia. Knoow Enciclopédia Temática, 2016. Disponível em: <http://knoow.net/ciencsociaishuman/psicologia/normopatia/>. Acesso em: 18 jul. 2016.

FOUCAULT, Michel. História da loucura na Idade Clássica. 10. ed. São Paulo: Perspectiva, 2014. 551 p. 
FRAGALÁ, Grácia Elisabeth. O ambiente de trabalho e o adoecimento do trabalhador. In: RAZZOUK, Denise; LIMA, Mauro Gomes Aranha de; CORDEIRO, Quirino (Orgs.). Saúde mental e trabalho. São Paulo: Conselho Regional de Medicina do Estado de São Paulo - Cremesp, 2015. Cap. 5. p. 91-110.

FRANCO, Tânia; DRUCK, Graça; SELIGMANN-SILVA, Edith. As novas relações de trabalho, o desgaste mental do trabalhador e os transtornos mentais no trabalho. Revista Brasileira de Saúde Ocupacional: RBSO, São Paulo, v. 122, n. 35, p.229-248, out. 2010. Disponível em: <http:||redalyc.org/articulo.oa?id=100515726006>. Acesso em: 19 maio 2016.

FUNDACENTRO. Disponível em: <www.fundacentro.gov.br>.

GAIA, Fausto Siqueira. A tutela Inibitória de ofício e a proteção do meio ambiente do trabalho: limites e possibilidades da atuação jurisdicional. São Paulo: LTr, 2015. 151 p.

GAIOLA, Vera et al. Segurança e saúde no trabalho da condução automóvel profissional: riscos profissionais e medidas preventivas. Lisboa: ACT, 2016. Disponível em: <http://www.acisb.pt/pt/images/MANUAL_SST_CONDUÇÃO_AUTOMÓVEL_PROFIS SIONAL_FINAL.pdf>. Acesso em: 04 jan. 2018.

GEDIEL, José Antonio Peres; MELLO, Lawrence Estivalet de. Estatuto jurídico do trabalho, formas de regulação e assédio moral. In: GEDIEL, José Antonio Peres et al (Orgs.). Estado, poder e assédio: relações de trabalho na administração pública. Curitiba: Kairós, 2015. p. 93-126.

GLINA, Débora Miriam Raab; ROCHA, Lys Esther. Aspectos preventivos em psiquiatria ocupacional. In: CAMARGO, Duílio Antero de; CAETANO, Dorgival; GUIMARÃES, Liliana Andolpho (Orgs.). Psiquiatria ocupacional: aspectos conceituais, diagnósticos e periciais dos transtornos mentais e do comportamento relacionados ao trabalho. São Paulo: Atheneu, 2010. p. 153-166.

GOBIERNO DE ESPAÑA. Instituto Nacional de Seguridad e Higiene en el Trabajo. Ley 31/1995, de 8 de noviembre, de Prevención de Riesgos Laborales. BOE $\mathrm{n}^{\circ} 269$ 10- 11$1995 . \quad$ Disponível em: <http://www.insht.es/InshtWeb/Contenidos/Normativa/TextosLegales/LeyPrevencion/PDF s/leydeprevencionderiesgoslaborales.pdf >. Acesso em: 01 nov. 2016.

GOLDSCHMIDT, Rodrigo. Flexibilização dos direitos trabalhistas: ações afirmativas da dignidade da pessoa humana como forma de resistência. São Paulo: LTr, 2009. 216 p.

GORZ, André. O imaterial: conhecimento, valor e capital. Tradução de Celso Azzan Jr. São Paulo: Anablume, 2005. 108 p.

. Misérias do presente, riqueza do possível. Tradução de Ana Montoia. São Paulo: Anablume, 2004. 164 p.

GUEDES, Márcia Novaes. Terror psicológico no trabalho. 3. ed. São Paulo: LTr, 2008. $175 \mathrm{p}$. 
GUIMARÃES, Liliana Andolpho Magalhães et al. Hardiness (personalidade resistente) e trabalho. In: GUIMARÃES, Liliana Andolpho Magalhães; GRUBITS, Sonia (Orgs.). Saúde mental e trabalho. São Paulo: Casa do Psicólogo, 2008. v. 34, p. 43-56.

et al. Psicologia da saúde ocupacional (PSO): um campo emergente. In: GUIMARÃES, Liliana Andolpho Magalhães; GRUBITS, Sonia (Orgs.). Saúde mental e trabalho. São Paulo: Casa do Psicólogo, 2008. v. 34. p. 23-32.

et al. Saúde mental do trabalhador e contemporaneidade. In: GUIMARÃES, Liliana Andolpho Magalhães; CAMARGO, Dúlio Antero de; SILVA, Myryam C. Maziero Vergueiro da (Orgs.). Temas e pesquisas em saúde mental e trabalho. Curitiba: CRV, 2015. Cap. 1. p. 15-36.

; RIMOLI, Adriana Odalia. "Mobbing" (assédio psicológico) no trabalho: uma síndrome psicossocial multidimensional. Psicologia: teoria e pesquisa, Brasília, v. 22, n. 2, p.1-12, maio 2006. Disponível em: <http://www.scielo.br/scielo.php?script=sci_arttext\&pid=S0102-37722006000200008>. Acesso em: 03 maio 2017.

GUIVANT, Julia Silvia. O legado de Ulrich Beck. Ambiente e Sociedade, São Paulo, v. 19, n. 1, p.1-7, 19 dez. 2015. Disponível em: <http://scielo.php?pid=pid=S1414->. Acesso em: 06 nov. 2017.

HAMANN, Renan. A traumatizante rotina de um moderador de conteúdo nas redes sociais. 2014. Disponível em: <https://www.tecmundo.com.br/bizarro/64973-vida-ingratamoderador-conteudo-redes-sociais.htm>. Acesso em: 15 out. 2015.

HARNOIS, Gaston; GABRIEL, Phyllis (Org.). Mental health and work: impacts, issues and good practices. Geneva: World Health Organization, 2000. 67 p. Department of Mental Health and Substance Dependence. Noncommunicable diseases and Mental Health. Disponível em: <www.ilo.org/wcmsp5/groups/public/skills/documents/publication/wcms_108152.pdf>. Acesso em: 10 abr. 2014.

HARVEY, David. Condição pós-moderna: uma pesquisa sobre as origens da mudança cultural. 24. ed. São Paulo: Loyola Jesuítas, 2013. 348 p.

HASSARD, Juliet; COX, Tom. Work-related stress: nature and management. 2017. OSHWiki. Disponível em: <https://oshwiki.eu/wiki/Workrelated_stress:Nature_and_management>. Acesso em: 11 jan. 2017.

HELOANI, Roberto; BARRETO, Margarida. Assédio moral nas relações sociais no âmbito das instituições públicas. In: GEDIEL, José Antonio Peres et al (Org.). Estado, poder e assédio: relações de trabalho na administração pública. Curitiba: Kairós, 2015. p. 145-162.

HIRIGOYEN, Marie-France. Mal-estar no trabalho: redefinindo o assédio moral. Tradução Rejane Janowitzer. 6. ed. Rio de Janeiro: Bertrand Brasil, 2011. 352 p. 
HUPKE, Marlen. Psychosocial risks and workers health. 2017. OSHWiki. Disponível em: <https://oshwiki.eu/wiki/Psychosocial_risks_and_workers_health>. Acesso em: 11 jan. 2017.

INTERNATIONAL LABOUR ORGANIZATION - ILO. Estrés en el trabajo: un reto colectivo. 2016. Día Mundial de la Seguridad Y La Salud en el Trabajo. Disponível em: <http://www.ilo.org/wcmsp5/groups/public/---ed_protect/---protrav/---

safework/documents/publication/wcms_466549.pdf>. Acesso em: 04 abr. 2016.

. Workplace stress: a collective challenge. World day for safety and health at work. 28 April 2016. Disponível em: <http://www.ilo.org/safework/info/publications/WCMS_466547/lang--en/index.htm>. Acesso em: 11 mar. 2017.

World day for safety and health at work: 28 Apr. 2016. Disponível em: <http://www.ilo.org/safework/events/safeday/lang--en/index.htm>. Acesso em: 20 jun. 2016.

JAKUTIS, Paulo. Manual de estudo da discriminação no trabalho: estudos sobre discriminação, assédio sexual, assédio moral e ações afirmativas, por meio de comparações entre o Direito do Brasil e dos Estados Unidos. São Paulo: LTr, 2006. 349 p.

KARASEK JUNIOR, Robert A. Job demands, job decision latitude and mental strain: implications for job redesig. Administrative Science Quarterly, Cornell, v. 24, n. 2, p.285308, jun. 1979. Disponível em: <https://www.jstor.org/stable/2392498?seq=1\#page_scan_tab_contents>. Acesso em: 04 jan. 2018.

KIRKLAND, Allegra. Moderadores relatam impacto psicológico de exposição a conteúdos impróprios na Internet. Opera Mundi. Disponível em: <http://operamundi.uol.com.br/conteudo/samuel/38479/moderadores+relatam+impacto+ps icologico+de+exposicao+a+conteudo+improprio+na+internet.shtml $>$. Acesso em: 11 nov. 2014.

LEÃO, Luís Henrique da Costa; VASCONCELLOS, Luiz Carlos Fadel de. Rede Nacional de Atenção Integral à Saúde do Trabalhador (RENAST): uma rede que não enreda. In: VASCONCELOS, Luiz Carlos Fadel de; OLIVEIRA, Maria Helena Barros de. Saúde, trabalho e direito: uma trajetória crítica e a crítica de uma trajetória. Rio de Janeiro: Educam, 2011. Cap. 10. p. 453-490.

LEITE, Carlos Henrique Bezerra. Manual de direitos humanos. 3. ed. São Paulo: Atlas, 2014. $181 \mathrm{p}$.

Tutela coletiva inibitória para proteção do meio ambiente do trabalho saudável. In: FELICIANO, Guilherme Guimarães et al (Orgs.). Direito ambiental do trabalho: apontamentos para uma teoria geral. São Paulo: LTr, 2015. v. 2, p. 137-151.

LINHART, Danièle. A desmedida do capital. Tradução Wanda Caldeira Brant. São Paulo: Boitempo, 2007. 244 p. 
LIPP, Marilda Emmanuel Novaes (Org.). O stress está dentro de você. 2. ed. São Paulo: Contexto, 2000.

LLORY, Michel; MONTMAYEUL, René. $O$ acidente e a organização. Tradução de Marlene Machado Zica Vianna. Belo Horizonte: Fabrefactum, 2014. 157 p.

LUKÁCS, György. Para uma ontologia do ser social II. Tradução de Carlos Nelson Coutinho. São Paulo: Boitempo, 2012.

MANCUSO, Rodolfo de Camargo. A ação civil pública como instrumento de controle judicial das chamadas políticas públicas. In: MILARÉ, Édis (Org.). Ação civil pública: lei 7.347/1985 - 15 anos. São Paulo: Revista dos Tribunais, 2002. p. 753-797.

MARANHÃO, Ney. Meio ambiente do trabalho: descrição jurídico-conceitual. Revista LTr, São Paulo, v. 80, n. 4, p.420-430, abr. 2016.

. Poluição labor-ambiental: abordagem conceitual da degradação das condições de trabalho, da organização do trabalho e das relações interpessoais travadas no contexto laborativo. Rio de Janeiro: Lumen Juris, 2017. 304p.

MARINONI, Luiz Guilherme. O direito à tutela jurisdicional efetiva na perspectiva da teoria dos direitos fundamentais. 2004. E.Gov. Portal de e-governo, inclusão digital e sociedade do conhecimento. Disponível em: <http://egov.ufsc.br/portal/sites/default/files/anexos/15441-15442-1-PB.pdf>. Acesso em: 05 out. 2016.

MARX, Karl. O capital: crítica da economia política. Tradução de Rubens Enderle. São Paulo: Boitempo, 2013. 894 p. (Livro I).

. Manuscritos econômicos filosóficos. Tradução, apresentação e notas Jesus Ranieri. São Paulo: Boitempo, 2010. 190 p.

; ENGELS, Friedrich. A ideologia alemã. São Paulo: Hucitec, 1999. 115 p.

; Manifesto do Partido Comunista. Tradução de Sueli Tomazini Barros Cassal. Porto Alegre: LPM, 2011. 132 p.

MELHADO, Reginaldo. Metamorfoses do capital e do trabalho: relações de poder, reforma do judiciário e competência da justiça laboral. São Paulo: LTr, 2006. 302 p.

MELO, Marlene Catarina de Oliveira Lopes; CASSINI, Meire Rose de Oliveira Loureiro; LOPES, Ana Lúcia Magri. Do estresse e mal-estar gerencial ao surgimento da Síndrome de Estocolmo Gerencial. Revista Psicologia: organizações e trabalho, Brasília, v. 11, n. 2, p.84-89, dez. 2011. Disponível em: <http://submissionpepsic.scielo.br/index.php/rpot/index>. Acesso em: 19 dez. 2017.

MELO, Raimundo Simão de. Direito ambiental do trabalho e a saúde do trabalhador: responsabilidades legais, dano material, dano moral, dano estético, indenização pela perda de uma chance / prescrição. 4. ed. São Paulo: LTr, 2010. 559 p. 
MERLO, Alvaro Crespo. Psicodinâmica do trabalho. In: JACQUES, Maria da Graça; COCO, Wanderlei (Orgs.). Saúde mental \& trabalho: leituras. Petrópolis: Vozes, 2002. p. $130-142$.

; BOTTEGA, Carla Garcia; PEREZ, Karine Vanessa. Atenção ao sofrimento e ao adoecimento psíquico do trabalhador e da trabalhadora: cartilha para profissionais do Sistema Único de Saúde - SUS. Porto Alegre: Evangraf, 2014. 28 p.

MILARÉ, Édis. Ação civil pública: lei 7.347/1985 - 15 anos. 2. ed. São Paulo: Revista dos Tribunais, 2002. $895 \mathrm{p}$.

MORAES, Alexandre de. Direitos humanos fundamentais: teoria geral, comentários aos arts. $1^{\circ}$ ao $5^{\circ}$ da Constituição da República Federativa do Brasil, doutrina e jurisprudência. São Paulo: Atlas, 2013. 413 p.

MOTA, Miriam Cristina Zaidan. Psicologia aplicada em segurança do trabalho: destaque nos aspectos comportamentais e trabalho em equipe da NR-10. São Paulo: LTr, 2015. 108 p.

NDJABOUÉ, Ruth et al. Effort-reward imbalance and medically certified absence for mental health problems: study of white-collar workers. Occupational and Environmental Medicine, Québec, v. 71, n. 1, p.40-47, jan. 2014. Groupe Interdisciplinaire de Recherche sur L'Organisation et la Santé au Travail (GIROST), Québec, C. Disponível em: <https://www.ncbi.nlm.nih.gov/pubmed/24174636>. Acesso em: 04 jan. 2018.

NEVES, Ingrid Cruz de Souza; NEVES, Isabelli Cruz de Souza; SILVA, Rinaldo Mouzalas de Souza e. Direito ambiental do trabalho: o meio ambiente do trabalho, uma aproximação disciplinar. In: FELICIANO, Guilherme Guimarães et al. (Orgs.). Direito ambiental do trabalho: apontamentos para uma teoria geral. São Paulo: LTr, 2015. v. 2, p. 13-20.

OLIVEIRA, Sebastião Geraldo de. Fundamentos da tutela labor-ambiental. In: FELICIANO, Guilherme Guimarães et al (Orgs.). Direito ambiental do trabalho: apontamentos para uma teoria geral. São Paulo: LTr, 2015. v. 2, p. 91-117.

Indenizações por acidente do trabalho ou doença ocupacional. 5. ed. São Paulo: LTr, 2009. 549 p.

Proteção Jurídica à saúde do trabalhador. 5. ed. São Paulo: LTr, 2010. 519 p.

ORGANIZACIÓN INTERNACIONAL DEL TRABAJO (OIT). Oficina Internacional del Trabajo. Enciclopedia de salud y seguridad en el trabajo. 3. ed. Madrid: Sociedad Española Oara Ek Estudio de la Ansiedad y el Estrés (SEAS), 2001. Disponível em: <http://www.mtas.es/es/publica/enciclo/default.htm>. Acesso em: 01 nov. 2017.

ORGANIZACIÓN MUNDIAL DE LA SALUD - OMS. Plan de acción sobre salud mental 2013-2020. 2013. Disponível em: <http://apps.who.int/iris/bitstream/10665/97488/1/9789243506029_spa.pdf>. Acesso em: 19 maio 2016. 
PADILHA, Norma Sueli. O equilíbrio do meio ambiente do trabalho: direito fundamental do trabalhador e de espaço interdisciplinar entre o direito do trabalho e o direito ambiental. Revista do TST, Brasília, v. 77, n. 4, p.231-256, dez. 2011. Disponível em: <https://juslaboris.tst.jus.br/handle/1939/21256>. Acesso em: 09 maio 2017.

Meio ambiente do trabalho: o diálogo entre o direito do trabalho e o direito ambiental. In: FELICIANO, Guilherme Guimarães et al (Orgs.). Direito ambiental do trabalho: apontamentos para uma teoria geral. São Paulo: LTr, 2015. v. 2, p. 105-121.

PAPARELLI, Renata; SATO, Leny; OLIVEIRA, Fábio de. A saúde mental relacionada ao trabalho e os desafios aos profissionais da saúde. Revista Brasileira de Saúde Ocupacional, São Paulo, v. 36, n. 123, p.118-127, 2011.

PENIDO, Laís de Oliveira; PERONE, Giancarlo. Saúde mental no trabalho: esclarecimentos para juristas. In: FELICIANO, Guilherme Guimarães et al (Orgs.). Direito ambiental do trabalho: apontamentos para uma teoria geral. São Paulo: LTr, 2015. v. 2, p. 499-506.

PILEGIS, Olga Regiane. Danos labor-ambientais: o caso "Recanto dos Pássaros" à luz dos princípios informadores do direito ambiental do trabalho. Revista do Departamento de Direito do Trabalho e da Seguridade Social, São Paulo, v. 7, n. 1, p. 252-276, jul. 2015/jun. 2016.

PINHEIRO, Marcelo de Andrade. Estratégias para a redução do impacto econômico dos transtornos mentais no ambiente de trabalho. In: RAZZOUK, Denise; LIMA, Mauro Gomes Aranha de; CORDEIRO, Quirino (Orgs.). Saúde mental e trabalho. São Paulo: Conselho Regional de Medicina do Estado de São Paulo - Cremesp, 2015. Cap. 12. p. 181-191.

PINTO, José Augusto Rodrigues. Ambientes saudáveis de trabalho. In: FELICIANO, Guilherme Guimarães et al (Orgs.). Direito ambiental do trabalho: apontamentos para uma teoria geral. São Paulo: LTr, 2015. v. 2, p. 81-87.

PIÑUEL Y ZABALA, Iñaki. Mobbing: como sobreviver ao assédio psicológico no trabalho. São Paulo: Edições Loyola, 2003. 313 p.

POLANCZYK, Guilherme V. Em busca das origens desenvolvimentais dos transtornos mentais. Revista de Psiquiatria do Rio Grande do Sul, Porto Alegre, v. 31, n. 1, p.6-12, 16 abr. 2009.

PONTES, Nádia. Informalidade, a cara da crise no Brasil. DMT em debate - democracia e mundo do trabalho, 05 mar. 2017. Disponível em: <http://www.dmtemdebate.com.br>. Acesso em: 22 fev. 2017.

PORTUGAL. Lei $\mathrm{n}^{\circ}$ 102/2009, de 10 de setembro de 2009. Regime Jurídico da Promoção da Saúde $e$ Segurança no Trabalho. Disponível em: <http://www.ilo.org/dyn/natlex/docs/SERIAL/82534/90431/F521393552/Ley 102.pdf>. Acesso em: 03 jan. 2018. 
PRATA, Marcelo Rodrigues. O direito ambiental do trabalho numa perspectiva sistêmica: as causas de inefetividade da proteção à ambiência laboral e o que podemos fazer para combatê-la. São Paulo: LTr, 2013. 254 p.

RAMAZZINI, Bernardino. As doenças dos trabalhadores. Tradução de De morbis artificum diatribe. 4. ed. São Paulo: Fundacentro, 2016. 321 p.

RAZZOUK, Denise. Capital mental, custos indiretos e saúde mental. In: RAZZOUK, Denise; LIMA, Mauro Gomes Aranha de; CORDEIRO, Quirino (Orgs.). Saúde mental e trabalho. São Paulo: Conselho Regional de Medicina do Estado de São Paulo - Cremesp, 2015. Cap. 3. p. 63-110.

Promoção de saúde mental no trabalho. In: RAZZOUK, Denise; LIMA, Mauro Gomes Aranha de; CORDEIRO, Quirino (Orgs.). Saúde mental e trabalho. São Paulo: Conselho Regional de Medicina do Estado de São Paulo - Cremesp, 2015a. Cap. 11. p. 171-180.

REIMBERG, Cristiane Oliveira. O exercício da atividade jornalística na visão dos profissionais: sofrimento e prazer na perspectiva teórica da psicodinâmica do trabalho. 2015. 376 f. Tese (Doutorado) - Curso de Ciências da Comunicação, Escola de Comunicações e Artes da Universidade de São Paulo, São Paulo, 2015.

RIBEIRO, Wallace Carvalho; LOBATO, Wolney; LIBERATO, Rita de Cássia. Notas sobre fenomenologia, percepção e educação ambiental: Revista Sinapse, 2009. Disponível em: <www.pucminas.br/graduação/cursos/arquivos>. Acesso em: 16 nov. 2015.

RIOS, Roger Raupp. Assédio moral sexual: conceito jurídico e prova. In: GEDIEL, José Antonio Peres et al (Orgs.). Estado, poder e assédio: relações de trabalho na administração pública. Curitiba: Kairós, 2015. p. 73-91.

ROCHA, Fábio Lopes; HARA, Cláudia; PAPROCKI, Jorge. Doença mental e estigma. Revista Médica de Minas Gerais, Belo Horizonte, v. 25, n. 4, p.1-10, mar. 2015. Disponível em: <http://www.rmmg.org/artigo/detalhes/1876>. Acesso em: 4 jan. 2018.

ROCHA, Julio Cesar de Sá da. Direito ambiental do trabalho: reflexo da contemporaneidade. Revista de Direito Sanitário, São Paulo, v. 3, n. 1, p.118-133, 30 mar. 2002.

RODRIGUES JUNIOR, Edson Beas (Org.). Convenções da OIT e outros instrumentos de direito internacional público e privado relevantes ao direito do trabalho. 2. ed. São Paulo: LTr, 2015. 727 p.

ROMITA, Arion Sayão. Direitos fundamentais nas relações de trabalho. 5. ed. São Paulo: LTr, 2014. 509 p.

ROVER, Tadeu. Para juiz, fotógrafo é culpado por levar tiro em protesto que o deixou cego de um olho. Consultor Jurídico, 17 ago. 2016. Disponível em: <http://www.conjur.com.br/2016-ago-17/fotografo-culpado-tiro-deixou-cego-protestojuiz?>. Acesso em: 17 ago. 2016. 
RUIZ, Valéria Salek; ARAUJO, André Luis Lima de. Saúde e segurança e a subjetividade no trabalho: os riscos psicossociais. Revista Brasileira de Saúde Ocupacional, São Paulo, v. 37, n. 125, p.170-180, 2012. Disponível em: <http://www.scielo.br/pdf/rbso/v37n125/a20v37n125.pdf >. Acesso em: 12 dez. 2016.

SAUVAJOL-RIALLAND, Caroline. Droit à la déconnexion: inventer un nouveau modéle de gouvernance. Le Monde.fr. 2014. Disponível em: <hoop://www.lemonde.fr/idees/article/2014/10/2016/droit-a-la-deconnexion-inventer-unnouveau-modele-degouvernance_4507659_3232.html>. Acesso em: 17 out. 2014.

SCHINESTSCK, Clarissa Ribeiro. A tutela inibitória coletiva como instrumento de efetivação do direito ao meio ambiente do trabalho equilibrado. In: GUIMARÃES, Liliana Andolpho Magalhães et al (Orgs.). Direito ambiental do trabalho: apontamentos para uma teoria geral. São Paulo: LTr, 2017. p. 181-222.

SCHMIDT, Martha Halfeld Furtado de Mendonça. A Organização Internacional do Trabalho: uma agência das Nações Unidas para a efetividade dos direitos trabalhistas. In: SENA, Adriana Goulart de; DELGADO, Gabriela Neves; NUNES, Raquel Portugal (Orgs.). Dignidade humana e inclusão social: caminhos para a efetividade do direito do trabalho no Brasil. São Paulo: LTr, 2010. Cap. 23. p. 464-480.

Trabalho e saúde mental na visão da OIT. Revista do Tribunal Regional do Trabalho da $3^{a}$ Região, Belo Horizonte, v. 51, n. 81, p.489-516, jun. 2010-a.

SELIGMANN-SILVA, Edith. A precarização contemporânea: a saúde mental no trabalho precarizado. In: VIZZACCARO-AMARAL, André Luís; MOTA, Daniel Pestana; ALVES, Giovanni (Orgs.). Trabalho e estranhamento: saúde e precarização do homem-quetrabalha. São Paulo: LTr, 2012. Cap. 4. p. 87-111.

. Trabalho e desgaste mental: o direito de ser dono de si mesmo. São Paulo: Cortez, 2011. $622 \mathrm{p}$.

; FIGUEIREDO, Marcelo; FRANCO, Tânia. As relações contemporâneas entre meio ambiente, trabalho e saúde mental. In: FELICIANO, Guilherme Guimarães et al (Orgs.). Direito ambiental do trabalho: apontamentos para uma teoria geral. São Paulo: LTr, 2015. p. 507-547.

SIEGRIST, Johannes. Adverse health effects of high-effort/low-reward conditions. Journal of Occupational Health Psychology, Düsseldorf, v. 1, n. 1, p.27-41, 1996. Disponível em: <https://pdfs.semanticscholar.org/79da/fe09b439dff93d0cf4f4a0d231fff321e0a4.pdf>. Acesso em: 04 jan. 2018.

SILVA, Homero Batista Mateus da. Curso de direito do trabalho aplicado: saúde e segurança do trabalho. 2. ed. São Paulo: Revista dos Tribunais, 2015. 349 p. (Coleção curso de direito do trabalho aplicado; v.3).

SILVA, José Antonio Ribeiro de Oliveira; SARDÁ, Sandro Eduardo. Perícias judiciais multiprofissionais e a lei do ato médico: por uma interpretação que leve em conta a unidade do sistema e a efetividade da prestação jurisdicional. Revista do Tribunal Regional do Trabalho da 15ª Região, Campinas, n. 44, p.61-96, 2014. 
SILVA-JUNIOR, João Silvestre da. Transtornos mentais e comportamentais relacionados ao trabalho: a aplicação do nexo técnico epidemiológico previdenciário (NTEP). In: RAZZOUK, Denise; LIMA, Mauro Gomes Aranha de; CORDEIRO, Quirino (Orgs.). Saúde mental e trabalho. São Paulo: Conselho Regional de Medicina do Estado de São Paulo - Cremesp, 2015. Cap. 21. p. 291-300.

; FISCHER, Frida Marina. Absenteísmo-doença por transtornos mentais e comportamentais: fatores associados ao afastamento, tempo para retorno ao trabalho e impacto na Previdência Social. In: RAZZOUK, Denise; LIMA, Mauro Gomes Aranha de; CORDEIRO, Quirino (Orgs.). Saúde mental e trabalho. São Paulo: Conselho Regional de Medicina do Estado de São Paulo - Cremesp, 2015. Cap. 10. p. 159-166.

; _. Afastamento do trabalho por transtornos mentais e estressores psicossociais ocupacionais. Revista Brasileira de Epidemiologia, São Paulo, v. 18, n. 4, p.1-8, dez. 2015a. Disponível em: <http://dx.doi.org/10.1590/1980549720150000400005>. Acesso em: 07 fev. 2017.

SILVEIRA, Marco Antonio; KIKUCHI, Letícia Sayuri. Aspectos psicossociais nas organizações: desempenho competitivo com saúde para o trabalhador. In: RAZZOUK, Denise; LIMA, Mauro Gomes Aranha de; CORDEIRO, Quirino (Orgs.). Saúde mental e trabalho. São Paulo: Conselho Regional de Medicina do Estado de São Paulo - Cremesp, 2015. Cap. 2. p. 47-62.

SPERB, Paula. Bomba-relógio de suicídios: como uma mescla de agrotóxicos, depressão e dívidas abala grupo de agricultores gaúchos. UOL Notícias, 04 out. 2016. Disponível em: <noticias.uol.com.br/saude/ultimas-noticias/bbc/2016/10/04>. Acesso em: 30 out. 2016.

STANDING, Guy. O precariado: a nova classe perigosa. Belo Horizonte: Autêntica, 2014. $285 \mathrm{p}$.

SUMI, Leika Garcia et al. Conceitos sobre perícias médicas psiquiátricas no mundo do trabalho. In: RAZZOUK, Denise; LIMA, Mauro Gomes Aranha de; CORDEIRO, Quirino (Orgs.). Saúde mental e trabalho. São Paulo: Conselho Regional de Medicina do Estado de São Paulo - Cremesp, 2015. Cap. 19. p. 263-289.

SZABÓ JUNIOR, Adalberto Mohai. Manual de Segurança, higiene e medicina do trabalho. 9. ed. São Paulo: Rideel, 2015. 1133 p.

SZNELWAR, Laerte et al (Orgs.). Trabalhar na magistratura, construção da subjetividade, saúde e desenvolvimento profissional. Equipe de Pesquisa Fundação Vanzolini. Brasília: Conselho Nacional de Justiça, 2015. 136 p. (Justiça e Pesquisa).

TOLEDO, Tallita Massucci. A saúde mental do empregado como direito fundamental $e$ sua eficácia na relação empregatícia. São Paulo: LTr, 2011. 144 p.

TRABAlHO SEGURO. Programa Nacional de Prevenção de Acidentes de Trabalho. Disponível em: <http://www.tst.jus.br/web/trabalhoseguro/apresentacao2>. 
TRIBUNAL REGIONAL DO TRABALHO 24ㄹ REGIÃO - Mato Grosso do Sul. História: a criação da CLT. 2013. Disponível em: <https://trt24.jusbrasil.com.br/noticias/100474551/historia-a-criacao-da-clt>. Acesso em: 03 jan. 2018.

VASCONCELLOS, Luiz Carlos Fadel de. Entre a saúde ocupacional e a saúde do trabalhador: as coisas nos seus lugares. In: VASCONCELOS, Luiz Carlos Fadel de; OLIVEIRA, Maria Helena Barros de (Orgs.). Saúde, trabalho e direito: uma trajetória crítica e a crítica de uma trajetória. Rio de Janeiro: Educam, 2011. Cap. 8. p. 401-422.

As relações saúde-trabalho-direito e a justiça injusta. In: VASCONCELOS, Luiz Carlos Fadel de; OLIVEIRA, Maria Helena Barros de (Orgs.). Saúde, trabalho e direito: uma trajetória crítica e a crítica de uma trajetória. Rio de Janeiro: Educam, 2011. Cap. 1. p. 33-83.

; CAVALIERE, Ivonete. Relações saúde-trabalho fora de foco: o desenvolvimento insustentável. In: VASCONCELOS, Luiz Carlos Fadel de; OLIVEIRA, Maria Helena Barros de (Orgs.). Saúde, trabalho e direito: uma trajetória crítica e a crítica de uma trajetória. Rio de Janeiro: Educam, 2011. Cap. 11. p. 491-557.

VENEZUELA. Congreso de la República de Venezuela. Ley Orgánica del Trabajo de Venezuela. Decreto $N^{o}$ 8.938. 30 de abril de 2012. Disponível em: $<$ http://www.defiendete.org/html/deinteres/LEYES\%20DE\%20VENEZUELA/LEYES\%20DE\%20VENEZUELA\%20II/LEY \%20ORGANICA\%20DEL\%20TRABAJO.htm>.

VIEIRA, Carlos Eduardo Carrusca. Traumas no trabalho: uma nova leitura do Transtorno de Estresse Pós-traumático. Curitiba: Juruá, 2014. 296 p.

WORLD HEALTH ORGANIZATION (WHO). World Health Day 2017. Disponível em: <http://www.who.int/campaigns/world-health-day/2017/toolkit.pdf?ua=1>.

ZAHER, Vera Lucia; SILVA-JUNIOR, João Silvestre da; LUZ, Leonardo Sérvio. Bioética, saúde mental e trabalho. In: RAZZOUK, Denise; LIMA, Mauro Gomes Aranha de; CORDEIRO, Quirino (Orgs.). Saúde mental e trabalho. São Paulo: Conselho Regional de Medicina do Estado de São Paulo - Cremesp, 2015. Cap. 18. p. 249-262. 